\title{
The Role of High-Latitude Waves in the Intraseasonal to Seasonal Variability of Tropical Upwelling in the Brewer-Dobson Circulation
}

\author{
REI UEYAMA \\ Earth Science Division, NASA Ames Research Center, Moffett Field, California \\ EDWIN P. GERBER \\ Center for Atmosphere Ocean Science, Courant Institute of Mathematical Sciences, New York University, New York, New York \\ JoHn M. WALlace AND DARGAN M. W. Frierson \\ Department of Atmospheric Sciences, University of Washington, Seattle, Washington
}

(Manuscript received 18 June 2012, in final form 15 January 2013)

\begin{abstract}
The forcing of tropical upwelling in the Brewer-Dobson circulation (BDC) on intraseasonal to seasonal time scales is investigated in integrations of an idealized general circulation model, ECMWF Interim ReAnalysis, and lower-stratospheric temperature measurements from the (Advanced) Microwave Sounding Unit, with a focus on the extended boreal winter season. Enhanced poleward eddy heat fluxes in the high latitudes $\left(45^{\circ}-90^{\circ} \mathrm{N}\right)$ at the 100 -hPa level are associated with anomalous tropical cooling and anomalous warming on the poleward side of the polar night jet at the 70-hPa level and above. In both the model and the observations, planetary waves entering the stratosphere at high latitudes propagate equatorward to the subtropics and tropics at levels above $70 \mathrm{hPa}$ over an approximately 10-day period, exerting a force at sufficiently low latitudes to modulate the tropical upwelling in the upper branch of the BDC, even on time scales longer than the radiative relaxation time scale of the lower stratosphere. To the extent that they force the BDC via downward as opposed to sideways control, planetary waves originating in high latitudes contribute to the seasonally varying climatological mean and the interannual variability of tropical upwelling at the 70-hPa level and above. Their influence upon the strength of the tropical upwelling, however, diminishes rapidly with depth below $70 \mathrm{hPa}$. In particular, tropical upwelling at the cold-point tropopause, near $100 \mathrm{hPa}$, appears to be modulated by variations in the strength of the lower branch of the BDC.
\end{abstract}

\section{Introduction}

The Lagrangian mean meridional circulation that ventilates the stratosphere, commonly referred to as the Brewer-Dobson circulation (BDC), is marked by low-latitude ascent and high-latitude descent (Brewer 1949; Dobson 1956; Andrews et al. 1987). Adiabatic cooling in the ascending branch maintains tropical lowerstratospheric temperatures below radiative equilibrium values (Andrews et al. 1987; Gettelman et al. 2004; Corti et al. 2005).

Corresponding author address: Rei Ueyama, Earth Science Division, NASA Ames Research Center, Mail Stop 245-5, Moffett Field, CA 94035.

E-mail: rei.ueyama@nasa.gov
The BDC is driven mainly by the dissipation of vertically propagating Rossby and gravity waves originating in the extratropical winter hemisphere (Garcia 1987; Holton 1990; Haynes et al. 1991; Iwasaki 1992). The Rossby waves are of two kinds: planetary-scale waves originating in high latitudes of the winter hemisphere and synoptic-scale baroclinic waves originating in the midlatitudes of both winter and summer hemispheres (Held and Hoskins 1985; Plumb 2002; Shepherd 2007). The BDC can be viewed as consisting of an upper branch driven by the breaking of the deeper wintertime planetary-scale waves from the high latitudes (hereafter, "high-latitude planetary waves") and a lower branch driven by the breaking of the shallower synoptic-scale baroclinic waves just equatorward of the subtropical tropospheric jets, as depicted in Fig. 2 of Plumb (2002) 
and Fig. 13.14 of Vallis (2006). Based on the analyses of the residual circulation trajectories, Birner and Bönisch (2011) showed that the two branches are distinguishable with more rapid cycling of air and larger mass fluxes in the shallower and narrower lower branch.

Diagnostics by Rosenlof (1995), Plumb and Eluszkiewicz (1999), Semeniuk and Shepherd (2001), Scott (2002), Boehm and Lee (2003), Zhou et al. (2006), Kerr-Munslow and Norton (2006), Geller et al. (2008), Deckert and Dameris (2008), Rosenlof and Reid (2008), Ryu and Lee (2010), Chen and Sun (2011), Garny et al. (2011), and Zhou et al. (2012) have shown unequivocally that the upwelling branch of the BDC is forced by wave breaking in the outer tropics or subtropics, in accordance with the downward control principle (Haynes and McIntyre 1987; Haynes et al. 1991; Holton et al. 1995). Wave breaking at higher latitudes is also capable of modulating the strength of the tropical upwelling via "sideways control" when the time scale of the wave forcing is shorter than that of the radiative relaxation of the lower stratosphere (Holton et al. 1995). If the high-latitude planetary waves propagate equatorward and break at subtropical latitudes, as they appear to do so in observations of McIntyre and Palmer (1983) and in models of Dunkerton et al. (1981) and McLandress and Shepherd (2009), they may contribute to the forcing of the timemean upwelling via "downward control," and thereby help to maintain the seasonally varying, climatologicalmean BDC.

Empirical studies of Iwasaki (1992), Yulaeva et al. (1994), Randel et al. (2002a,b), Salby and Callaghan (2002), Dhomse et al. (2008), and Ueyama and Wallace (2010) have shown that the strength of the upwelling in the tropical lower stratosphere varies in response to sporadic bursts of planetary wave activity entering the high-latitude stratosphere from below. It has been argued that the breaking of these waves drives the upper branch of the BDC, but the connection between episodic, intraseasonal variations in high-latitude planetary wave activity and the seasonal-mean tropical upwelling derived from downward control has yet to be clearly demonstrated.

The absence of clear empirical evidence of the connection between planetary wave activity in the vicinity of the polar night jet and the low-latitude wave forcing of tropical upwelling, as manifested in the downward control diagnostics, has led to suggestions that lowerstratospheric temperatures are modulated primarily by the eddy forcing of the lower branch of the BDC. KerrMunslow and Norton (2006) and Norton (2006) argued that the annual cycle in tropical cold-point temperature is driven by seasonal variations in the strength of the equatorial planetary waves, which break in the outer tropics, inducing equatorial upwelling at the cold-point tropopause around $90 \mathrm{hPa}$. Boehm and Lee (2003), Randel et al. (2008), Deckert and Dameris (2008), Rosenlof and Reid (2008), Ryu and Lee (2010), and Garny et al. (2011) have similarly proposed the link between tropical upwelling and convectively driven equatorial planetary waves. Studies of Rosenlof (1995), Plumb and Eluszkiewicz (1999), Semeniuk and Shepherd (2001), Scott (2002), Zhou et al. (2006), Randel et al. (2008), Geller et al. (2008), Chen and Sun (2011), Garny et al. (2011), and Zhou et al. (2012) have emphasized the breaking of synoptic-scale baroclinic waves from the midlatitudes in forcing the lower branch of the BDC. Whether the mass of air that upwells through the tropical cold-point tropopause descends mainly within the tropics or whether it is transported poleward and descends in the extratropics remains an open question.

To reach closure on the relative importance of highlatitude planetary waves, midlatitude synoptic-scale baroclinic waves, and equatorial planetary waves in forcing seasonal and nonseasonal variability of the tropical upwelling in the BDC, it will be necessary to determine the extent to which the episodic bursts of high-latitude planetary wave activity in the winter hemisphere lead to wave breaking in the subtropics and outer tropics, where downward control becomes applicable on sufficiently long time scales. An obstacle is the limited ability of the reanalysis datasets to resolve the temporal variations in tropical upwelling and the wave breaking events that give rise to them. In this study, we strive to overcome these limitations by analyzing nonseasonal variations in the time rate of change of zonal-mean temperature $\partial[T] / \partial t$ and of the zonal-mean temperature itself $[T]$, which serve as reliable proxies for the rate of ascent in the tropical lower stratosphere on time scales shorter and longer than the lower-stratospheric damping time, respectively.

As a guide in interpreting our observational results, we rely on an extended integration of an idealized general circulation model that produces a realistic simulation of the high-latitude planetary waves and their role in forcing the BDC. This work complements earlier studies that have used numerical models of varying degrees of complexity, from idealized (e.g., Dunkerton et al. 1981; Plumb and Eluszkiewicz 1999; Scott 2002; Boehm and Lee 2003; Zhou et al. 2006; Geller et al. 2008; Chen and Sun 2011) to more complex (e.g., Semeniuk and Shepherd 2001; Norton 2006; Deckert and Dameris 2008; McLandress and Shepherd 2009; Ryu and Lee 2010; Garny et al. 2011). The highly idealized nature of the model in this study leads to defects in the climatological features, as noted in later sections, but its simplicity enables us to focus on the role of high-latitude 
planetary waves. That it is able to reproduce key features of the observations in the absence of convectively driven equatorial planetary waves supports the notion that waves originating in the extratropics are capable of forcing variability of the upper branch of the BDC.

Section 2 describes the datasets used and the methods that are employed. Section 3 examines the structure of the tropical upwelling in the BDC as simulated in the model and in observations. The role of high-latitude wintertime planetary waves in forcing the variability of the tropical upwelling on intraseasonal to seasonal time scales is explored in section 4. In our analysis of the observations, we will draw a distinction between the forcing of the tropical upwelling at $70 \mathrm{hPa}$ and above, which is representative of the upper branch of the BDC, and the upwelling in the vicinity of the tropical coldpoint tropopause near $100 \mathrm{hPa}$, which is more strongly influenced by the lower branch of the BDC. The contrasting variability in tropical upwelling at the 70- and 100-hPa levels is discussed in section 5. Our results are summarized and interpreted in the context of previous work in section 6 .

\section{Data and methods}

This study compares the results of an idealized general circulation model and two sets of observation-based data. We use the pseudospectral, dry dynamical core model (Held and Suarez 1994) modified to more realistically represent the stratospheric circulation (Polvani and Kushner 2002). We analyze a 10 000-day, perpetualJanuary integration run with a vortex lapse rate $\Upsilon=$ $4 \mathrm{~K} \mathrm{~km}^{-1}$ at triangular truncation 42 (T42; Gaussian grid of about $2.8^{\circ}$ ) resolution and 40 vertical sigma (=pressure/surface pressure) levels that are spaced approximately evenly in log pressure height, as in Polvani and Kushner (2002). A large-scale surface topography of wavenumber $k=2$ and amplitude $h_{0}=3 \mathrm{~km}$ is added in the winter hemisphere between $25^{\circ}$ and $65^{\circ} \mathrm{N}$, centered at $45^{\circ} \mathrm{N}$. These parameter settings have been shown to produce realistic troposphere-stratosphere coupling (Gerber and Polvani 2009) and a realistic BDC (Gerber 2012). The reader is referred to these papers for a more detailed description of the model.

The 6-hourly global European Centre for MediumRange Weather Forecasts Interim Re-Analysis (ERAInterim; Dee et al. 2011) data are analyzed for the 32-yr period from 1 January 1979 to 31 December 2010. The data are gridded at $1.5^{\circ}$ latitude by $1.5^{\circ}$ longitude from $90^{\circ} \mathrm{S}$ to $90^{\circ} \mathrm{N}$ and 37 pressure levels from 1 to $1000 \mathrm{hPa}$. Except where specifically indicated, the study focuses on the nonseasonal variability defined as departures from the seasonally varying climatological mean computed from climatological daily means (i.e., 1 January 1979 2010, 2 January 1979-2010, . . , 31 December 1979-2010) from November through March. Data from 29 February of the leap years have been omitted.

The daily brightness temperature $(T)$ fields derived from the lower-stratospheric channel of version 3.2 of the Microwave Sounding Unit/Advanced Microwave Sounding Unit carried aboard National Oceanic and Atmospheric Administration satellites (hereafter, MSU-4) are also analyzed for the same period of record, November-March 1979-2010. The data are gridded at $2.5^{\circ} \times 2.5^{\circ}$ resolution and extend to $82.5^{\circ} \mathrm{N} / \mathrm{S}$. The weighting function of the lower-stratospheric channel is concentrated mainly in the $15-19-\mathrm{km}(30-150 \mathrm{hPa})$ layer, as detailed in the Remote Sensing Systems website (www.ssmi.com/msu/).

Zonal averaging is denoted by square brackets and primes denote departures from the zonal mean. The poleward eddy heat flux term is computed by averaging the 6-hourly products of the meridional wind $v^{\prime}$ and temperature $T^{\prime}$ anomalies around latitude circles and subtracting the climatological 6-hourly means at each latitude and pressure level (i.e., $\left[v^{\prime} T^{\prime}\right]$ minus the climatological 6-hourly mean value of $\left.\left[v^{\prime} T^{\prime}\right]\right)$. Daily means are computed by averaging the 6-hourly data. Time derivative fields of temperature $\partial[T] / \partial t$ are estimated as centered differences. For example, what we refer to as a "2-day time rate of change" is computed by subtracting the value on day -1 from the value on day +1 in the time series.

The residual circulation is estimated using the transformed Eulerian-mean (TEM) equations (Edmon et al. 1980; Andrews et al. 1987) based on eddy covariance statistics, where asterisks denote TEM variables. The TEM streamfunction $\psi^{*}$ in pressure coordinates is defined as

$$
\psi^{*}=\psi-2 \pi a g^{-1} \cos \varphi \frac{\left[v^{\prime} \theta^{\prime}\right]}{\partial_{p}[\theta]},
$$

where $a$ is the radius of the Earth, $g$ is gravity, $\varphi$ is latitude, and $\theta$ is potential temperature. The conventional streamfunction $\psi$ is computed from a downward vertical integration of $[v]$, using $\psi=0$ as the boundary condition at the top of the domain where the mass circulation approaches zero.

The empirical orthogonal function (EOF) patterns of $\psi^{*}$ displayed in this paper are obtained by regressing the $\psi^{*}$ field upon the standardized principal component (PC) time series computed from an EOF analysis of $\psi^{*}$ at specified pressure levels. The amplitudes of the patterns represent typical amplitudes of the anomalies associated with fluctuations in the respective EOF modes. 
Tests for statistical significance of the correlation and regression fields are based on the Student's $t$ test with the number of temporal degrees of freedom (or "effective sample size") estimated using Eq. (31) in Bretherton et al. (1999).

In section $4 \mathrm{c}$ on the analysis of the tropical upwelling on monthly and seasonal time scales, we utilize the variable $[T]^{*}$ defined as the local $[T]$ minus the globalmean $[T]$ at each level. Subtracting the global-mean $[T]$ helps eliminate the effects of volcanic eruptions and the long-term stratospheric cooling trend in the interannual variability. Additionally, the quasi-biennial oscillation was removed following the method described in Wallace et al. (1993). Briefly, the two leading PC time series derived from EOF analysis of low-pass filtered, deseasonalized equatorial zonal wind measurements at 10 70-hPa levels were linearly regressed out from monthly mean ERA-Interim and MSU-4 data.

\section{Structure of the tropical upwelling in the BDC}

The time-mean structure of the TEM streamfunction $\psi^{*}$ field in the model is shown in Fig. 1a and compared to the climatological-mean boreal winter structure of $\psi^{*}$ in ERA-Interim in Fig. 1b. The tropospheric contours highlighted with colored shading depict the tropical Hadley cells and their eddy-driven extension to higher latitudes. In this perpetual-January integration of the model, the simulated Southern Hemisphere $(\mathrm{SH})$ circulation cell is substantially stronger than observed because of the unrealistically strong baroclinic eddies in the model's summer hemisphere. The wave-driven BDC in the stratosphere is indicated by the upper set of contours that appear above the colored shading. As in the troposphere, the SH (summer) stratospheric circulation is too strong in the model: the BDC cells in the two hemispheres are of comparable strength in the simulation (Fig. 1a), whereas the Northern Hemisphere (NH) cell is clearly dominant in ERA-Interim (Fig. 1b) and stronger than its SH counterpart in boreal summer, shown in Fig. 1c. The hemispherically symmetric pattern of $\psi^{*}$ in the simulation resembles the climatological annual mean structure of $\psi^{*}$ in the reanalysis (not shown). Since the model does not simulate the effects of latent heating on tropical convection, the simulated tropical cold-point tropopause at about $200 \mathrm{hPa}$ is lower than observed.

The greater strength of the circulation in the $\mathrm{NH}$ winter stratosphere (Fig. 1b) than in the $\mathrm{SH}$ winter stratosphere (Fig. 1c) gives rise to the observed JanuaryFebruary peak in tropical lower-stratospheric upwelling and the associated temperature minimum noted by Reed and Vlcek (1969). In ERA-Interim, the tropical

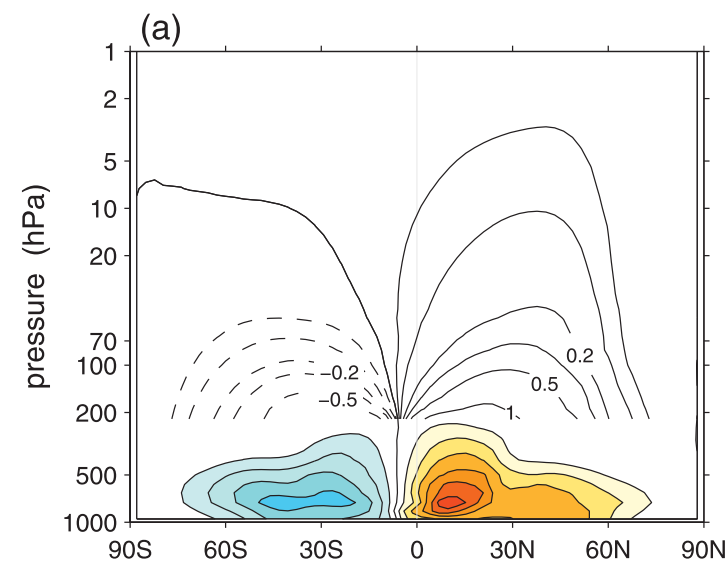

(b)

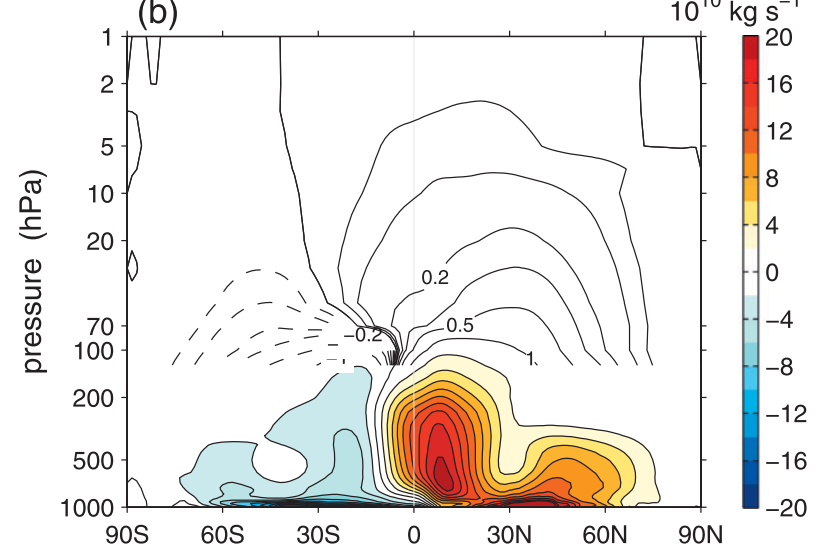

(c)

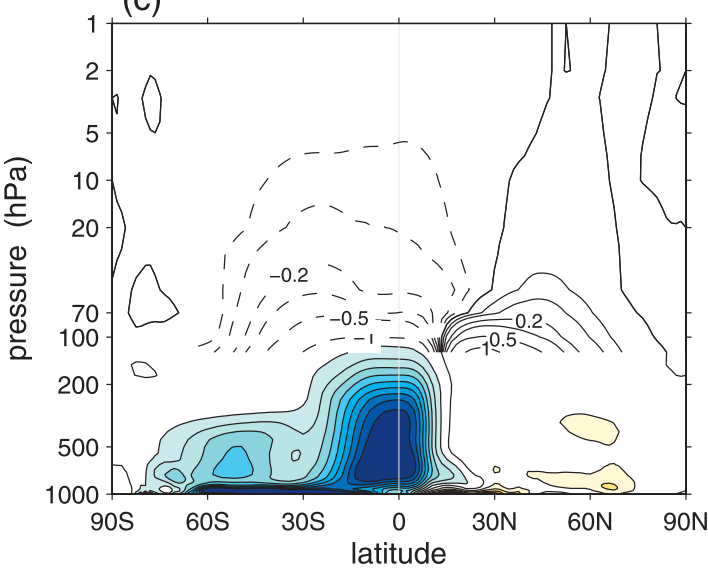

FIG. 1. (a) Vertical cross section of the time-mean $\psi^{*}$ field in the model simulation. (b),(c) As in (a), but based on December-February and June-August ERA-Interim (1979-2010) data, respectively. Contour values of $\psi^{*}$ are $\pm 0.05,0.1,0.2,0.3,0.5,1 \times$ $10^{10} \mathrm{~kg} \mathrm{~s}^{-1}$ at levels at or below (a) 220 and (b),(c) $150 \mathrm{hPa}$ with solid (dashed) lines representing positive (negative) values, and at an interval of $2 \times 10^{10} \mathrm{~kg} \mathrm{~s}^{-1}$ below those levels.

upwelling region widens from about $15^{\circ} \mathrm{S}-12^{\circ} \mathrm{N}$ in the troposphere to about $30^{\circ} \mathrm{S}-30^{\circ} \mathrm{N}$ in the lower stratosphere, illustrating the greater meridional width and the stronger equatorial symmetry of the upwelling 

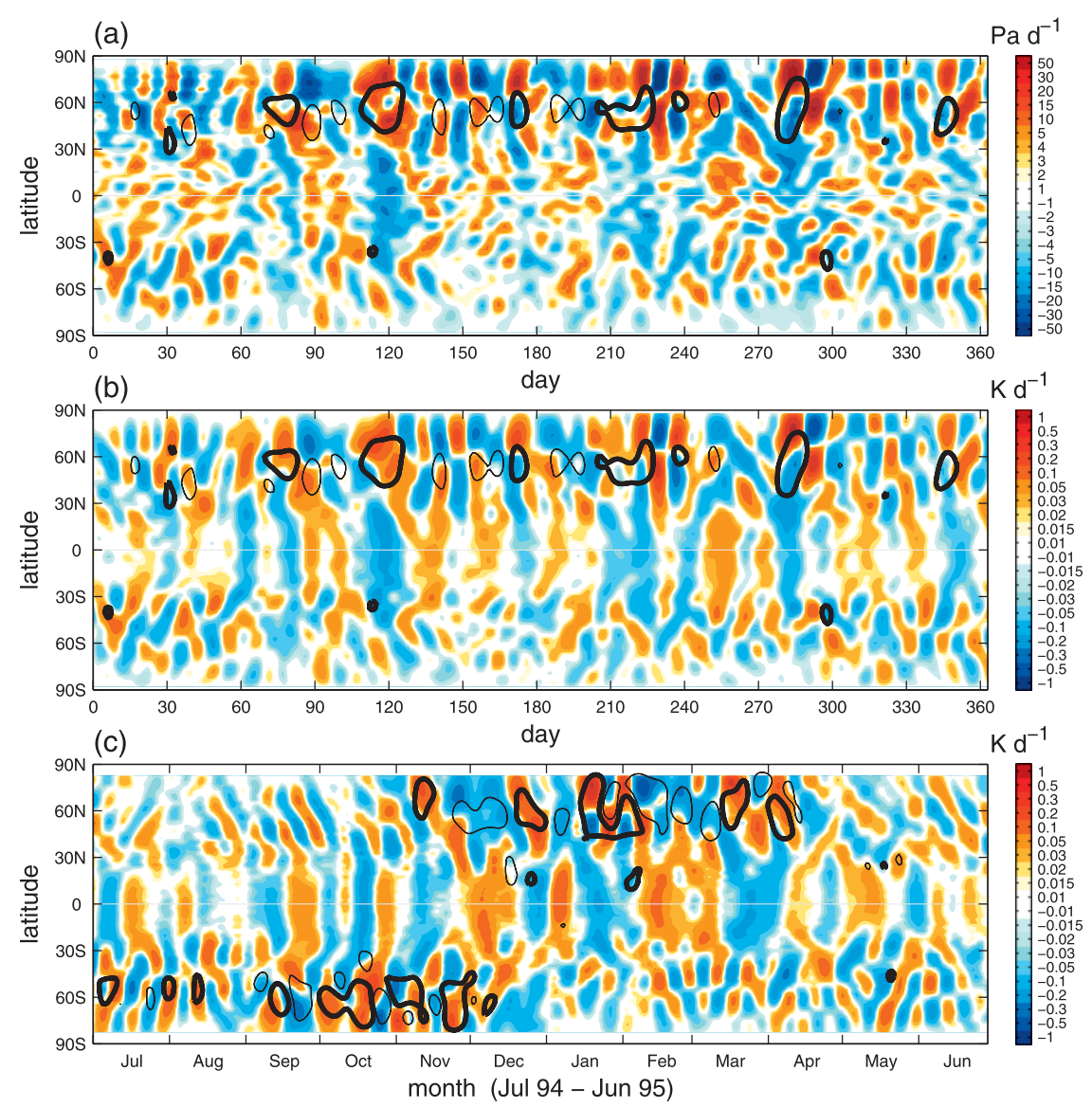

FIG. 2. Time-latitude sections of the $65-\mathrm{hPa}$ level (a) $\omega^{*}$ and (b) $\partial[T] / \partial t$ based on 10 -day Lanczos low-pass filtered model data. The $100-\mathrm{hPa}$ level $\left[v^{\prime} T^{\prime}\right]$ greater than $5 \mathrm{~m} \mathrm{~s}^{-1} \mathrm{~K}$ (less than $-5 \mathrm{~m} \mathrm{~s}^{-1} \mathrm{~K}$ ) during the same time period are plotted in thick (thin) black contours in the NH. (c) As in (b), but based on daily MSU-4 $\partial[T] / \partial t$ and ERA-Interim $\left[v^{\prime} T^{\prime}\right]$ (1 Jul 1994-30 Jun 1995). The sign of $\left[v^{\prime} T^{\prime}\right]$ is reversed in the SH such that positive $\left[v^{\prime} T^{\prime}\right]$ (thick contours) indicate poleward eddy heat fluxes in both hemispheres. All fields are weighted by the cosine of latitude.

branch of the BDC as compared with that of the Hadley cell.

The nonlinearly spaced contours depicting the stratospheric BDC are indicative of a change in the character of the circulation around the 70-hPa level in ERAInterim (Fig. 1b). The steep vertical gradient of $\psi^{*}$ below $70 \mathrm{hPa}$ in the tropics is indicative of a strong circulation that is concentrated near or just above the cold point. An estimate of the upward mass flux based on $\psi^{*}$ in Fig. $1 \mathrm{~b}$ indicates that only about $1 / 5$ of the mass of air that upwells through the $100-\mathrm{hPa}$ surface in the $15^{\circ} \mathrm{S}-$ $15^{\circ} \mathrm{N}$ latitudinal belt reaches the $70-\mathrm{hPa}$ level in ERAInterim, which is consistent with the vertical mass flux estimates of Corti et al. (2005) and Fu et al. (2007) derived from radiative transfer calculations. Above approximately $70 \mathrm{hPa}$, the contours are more evenly spaced and the $\psi^{*}$ values decrease more gradually with height, indicating a weaker but deeper equator-to-pole circulation.
This change in the vertical gradient of the streamfunction contours in ERA-Interim is suggestive of a distinction between the stronger, lower branch and the weaker, upper branch of the BDC.

The dominant temporal and meridional structure of the nonseasonal variability of the BDC becomes readily apparent in time-latitude sections shown in Fig. 2. Figure 2 a shows TEM pressure velocity $\left(\omega^{*}\right)$ anomalies at $65 \mathrm{hPa}$ during a selected 365-day period in the simulation. Nonseasonal variability of the upwelling is dominated by variations on intraseasonal time scales, primarily on the order of 10 days. The meridional structure of the variations resembles the time-mean structure of $\psi^{*}$ (Fig. 1), with broad, equatorially symmetric perturbations encompassing the entire tropical belt out to about $30^{\circ}$ latitude. Tropical $\omega^{*}$ anomalies are usually flanked by anomalies of opposing sign in the winter hemisphere, in this case the $\mathrm{NH}$, consistent with the conservation of mass. 
TABLE 1. Correlation coefficients between 10-day Lanczos low-pass filtered daily time series (ERA-Interim and MSU-4, NovemberMarch 1979-2010): high-latitude $\left(45^{\circ}-90^{\circ} \mathrm{N}\right)\left[v^{\prime} T^{\prime}\right]$ at $100 \mathrm{hPa}$; tropical $\left(30^{\circ} \mathrm{S}-30^{\circ} \mathrm{N}\right) \omega^{*}$ at $70 \mathrm{hPa}$; tropical $\left(30^{\circ} \mathrm{S}-30^{\circ} \mathrm{N}\right) \partial[T] / \partial t$ at $70-\mathrm{hPa}$, 100-hPa, and MSU-4 levels; PC 1 of daily $\psi^{*}$ at $70 \mathrm{hPa}$; and PC 3 of daily $\psi^{*}$ at $100 \mathrm{hPa}$. All correlations are significant at the $99 \%$ level.

\begin{tabular}{|c|c|c|c|c|c|c|c|}
\hline & $\begin{array}{c}\text { High-latitude } \\
{\left[v^{\prime} T^{\prime}\right] \text { at } 100 \mathrm{hPa}}\end{array}$ & $\begin{array}{l}\text { Tropical } \omega^{*} \\
\text { at } 70 \mathrm{hPa}\end{array}$ & $\begin{array}{c}\text { Tropical } \partial[T] / \partial t \\
\text { at } 70 \mathrm{hPa}\end{array}$ & $\begin{array}{l}\text { Tropical } \partial[T] / \partial t \\
\text { at } 100 \mathrm{hPa}\end{array}$ & $\begin{array}{l}\text { Tropical } \partial[T] / \partial t \\
\text { at MSU-4 levels }\end{array}$ & $\begin{array}{l}\text { PC } 1 \text { of } \psi^{*} \\
\text { at } 70 \mathrm{hPa}\end{array}$ & $\begin{array}{l}\text { PC } 3 \text { of } \psi^{*} \\
\text { at } 100 \mathrm{hPa}\end{array}$ \\
\hline $\begin{array}{l}\text { High-latitude } \\
\qquad\left[v^{\prime} T^{\prime}\right] \text { at } 100 \mathrm{hPa}\end{array}$ & 1 & -0.45 & -0.51 & -0.24 & -0.62 & 0.76 & 0.69 \\
\hline Tropical $\omega^{*}$ at $70 \mathrm{hPa}$ & & 1 & 0.72 & 0.45 & 0.66 & -0.60 & -0.48 \\
\hline $\begin{array}{l}\text { Tropical } \partial[T] / \partial t \text { at } \\
\quad 70 \mathrm{hPa}\end{array}$ & & & 1 & 0.38 & 0.80 & -0.54 & -0.45 \\
\hline $\begin{array}{l}\text { Tropical } \partial[T] / \partial t \text { at } \\
100 \mathrm{hPa}\end{array}$ & & & & 1 & 0.49 & -0.27 & -0.27 \\
\hline $\begin{array}{l}\text { Tropical } \partial[T] / \partial t \text { at } \\
\text { MSU-4 levels }\end{array}$ & & & & & 1 & -0.57 & -0.44 \\
\hline $\mathrm{PC} 1$ of $\psi^{*}$ at $70 \mathrm{hPa}$ & & & & & & 1 & 0.88 \\
\hline PC 3 of $\psi^{*}$ at $100 \mathrm{hPa}$ & & & & & & & 1 \\
\hline
\end{tabular}

The same perturbations are even more clearly evident in the time-latitude section of the 2-day time rate of change of temperature at $65 \mathrm{hPa}$ for the same period, shown in Fig. 2b. Negative $\omega^{*}$ anomalies, indicative of enhanced upwelling, coincide with negative $\partial[T] / \partial t$ anomalies, indicative of anomalous cooling and vice versa. The strong positive correlation between tropical mean $\omega^{*}$ and $\partial[T] / \partial t$ at the $65-\mathrm{hPa}$ level follows directly from the TEM thermodynamic equation

$$
\underbrace{\frac{\partial[T]}{\partial t}}_{\mathrm{A}}+\underbrace{\left(\frac{\partial[T]}{\partial p}-\frac{R}{c_{p}} \frac{[T]}{p}\right) \omega^{*}}_{\mathrm{B}}=\underbrace{-\left([T]-\left[T_{e}\right]\right) / \tau}_{C},
$$

where $R$ is the gas constant and $c_{p}$ is the heat capacity of air at constant pressure. The zonal-mean diabatic heating in the model is driven by Newtonian relaxation to a radiative equilibrium profile $T_{e}$ with radiative time scale $\tau=40$ day $^{-1}$ in the free troposphere and stratosphere. Newtonian relaxation is a useful approximation of the diabatic heating in the real atmosphere (e.g., Andrews et al. 1987) with $\tau \approx 30-60$ day $^{-1}$ in the lower stratosphere (e.g., Newman and Rosenfield 1997; Randel et al. 2002a). For time scales longer than $\tau$, the dominant balance is between terms B and C in Eq. (2), such that upwelling and temperature vary with opposite phase. On time scales much shorter than $\tau$, however, terms A and $B$ tend to balance and upwelling varies in phase with a tendency toward cooling.

Planetary-scale fluctuations in $\partial[T] / \partial t$, with broad and equatorially symmetric perturbations in the tropics flanked by perturbations of opposing sign, are also apparent in the observations, as evidenced by the section of $\partial[T] / \partial t$ based on MSU-4 data, shown in Fig. 2c. As in the simulation, the successive bands of anomalous cooling and warming are remarkably symmetric across the tropics out to about $30^{\circ}$ latitude and are flanked by strong anomalies of the opposing sign in high latitudes of the winter hemisphere. Fluctuations in $\omega^{*}$ at $70-\mathrm{hPa}$ in ERA-Interim (not shown) are dominated by highfrequency variability and are not as well correlated with variations in $\partial[T] / \partial t$ at the same level as in the model: $r=0.72$ in ERA-Interim versus 0.94 in the model (Table 1). Since we are not convinced that the data assimilated in ERA-Interim yield reliable vertical velocities, we use $\partial[T] / \partial t$ as a proxy for high-frequency variations in vertical velocity in the observed BDC.

\section{Role of high-latitude wintertime planetary waves}

As an indicator of the upward propagation of waves into the stratosphere, we superimpose $100-\mathrm{hPa}$ poleward eddy heat flux $\left[v^{\prime} T^{\prime}\right]$ anomalies greater than $5 \mathrm{~m} \mathrm{~s}^{-1} \mathrm{~K}$ on the time-latitude sections in Fig. 2. Eddy heat fluxes are associated with the vertical propagation of Rossby wave activity, as quantified in the EliassenPalm (EP) flux (Andrews and McIntyre 1976; Edmon et al. 1980). Episodes of strong poleward $\left[v^{\prime} T^{\prime}\right]$, centered around $60^{\circ}$ latitude, are associated with strong tropical upwelling/cooling in the model (e.g., day $\sim 120$ in Figs. 2a,b) and in the observations (e.g., mid-January 1995 in Fig. 2c). Similarly, anomalously weak fluxes tend to occur in concert with weak tropical upwelling/warming (e.g., day $\sim 160$ and February 1995). The high-latitude $100-\mathrm{hPa}\left[v^{\prime} T^{\prime}\right]$ are primarily associated with planetaryscale waves; Polvani and Waugh (2004) show that such bursts of upward wave propagation often precede stratospheric sudden warming events. The strong correspondence between enhanced high-latitude $\left[v^{\prime} T^{\prime}\right]$ and tropical upwelling/cooling in Fig. 2 suggests that planetary wave propagation into the high-latitude stratosphere is linked 
to the forcing of the tropical upwelling in both the simulation and in the observations.

\section{a. Variability on intraseasonal ( $\sim 10$ day) time scales}

We first investigate the intraseasonal variations in tropical upwelling, which dominate the overall nonseasonal variability of the BDC. To firmly establish the link between wave activity entering the high-latitude stratosphere and tropical upwelling suggested in Fig. 2, we define an index of high-latitude wave activity: deviations of $\left[v^{\prime} T^{\prime}\right]$ from climatology at the 100-hPa level, integrated from $45^{\circ}$ to $90^{\circ} \mathrm{N}$. Regressions of the $\left[v^{\prime} T^{\prime}\right]$ field upon this index and $100-\mathrm{hPa}\left[v^{\prime} T^{\prime}\right]$ integrated over various latitudinal ranges poleward of about $40^{\circ} \mathrm{N}$ (not shown) indicate that this index is a robust measure of wave propagation into the high-latitude stratosphere. Figure 3 shows meridional profiles of lower-stratospheric $\omega^{*}$ and $\partial[T] / \partial t$ constructed by regressing these fields upon the high-latitude wave index at various lags. The response of the lower-stratospheric $\partial[T] / \partial t$ profiles to high-latitude wave propagation is remarkably similar in the simulation and the MSU-4 observations (Figs. 3b,c). Both show nearly instantaneous warming of the polarcap region and cooling of the tropics, consistent with an enhancement of the BDC, as confirmed by the $\omega^{*}$ section of the model shown in Fig. 3a. The polar warming, which implies a weakening of the stratospheric polar night jet, lasts for about 5 days and is followed by an interval of cooling associated with the recovery of the polar vortex. The equatorward propagation of the polar $\partial[T] / \partial t$ anomalies in Fig. 3 is also apparent in the timelatitude sections in Fig. 2.

The widespread tropical cooling in response to highlatitude planetary wave propagation takes place over the course of about 10 days, centered around the time of the peak wave propagation across the $100-\mathrm{hPa}$ surface (i.e., zero lag). In the observations (Fig. 3c), the maximum tropical cooling occurs at day +2 , but no such delay is evident in the simulation at the $65-\mathrm{hPa}$ level (Fig. 3b). The results based on correlation analysis, indicated by the colored shading in Fig. 3, show enhanced cooling on the equator and near $20^{\circ} \mathrm{S}$ and $20^{\circ} \mathrm{N}$, forming a three-prong feature that is more prominent in the simulation than in the observations. Strong poleward $\left[v^{\prime} T^{\prime}\right]$ at $100-\mathrm{hPa}$ over $45^{\circ}-90^{\circ} \mathrm{N}$ is also accompanied by a relatively weak and short-lived local cooling over approximately $30^{\circ}-60^{\circ} \mathrm{N}$ at day -2 , indicative of upwelling that appears first in midlatitudes and quickly spreads into and across the tropics.

Figure 4 shows the evolution of the temperature response to planetary waves entering the high-latitude stratosphere, as represented by the same high-latitude $100-\mathrm{hPa}\left[v^{\prime} T^{\prime}\right]$ index used in constructing Fig. 3. The
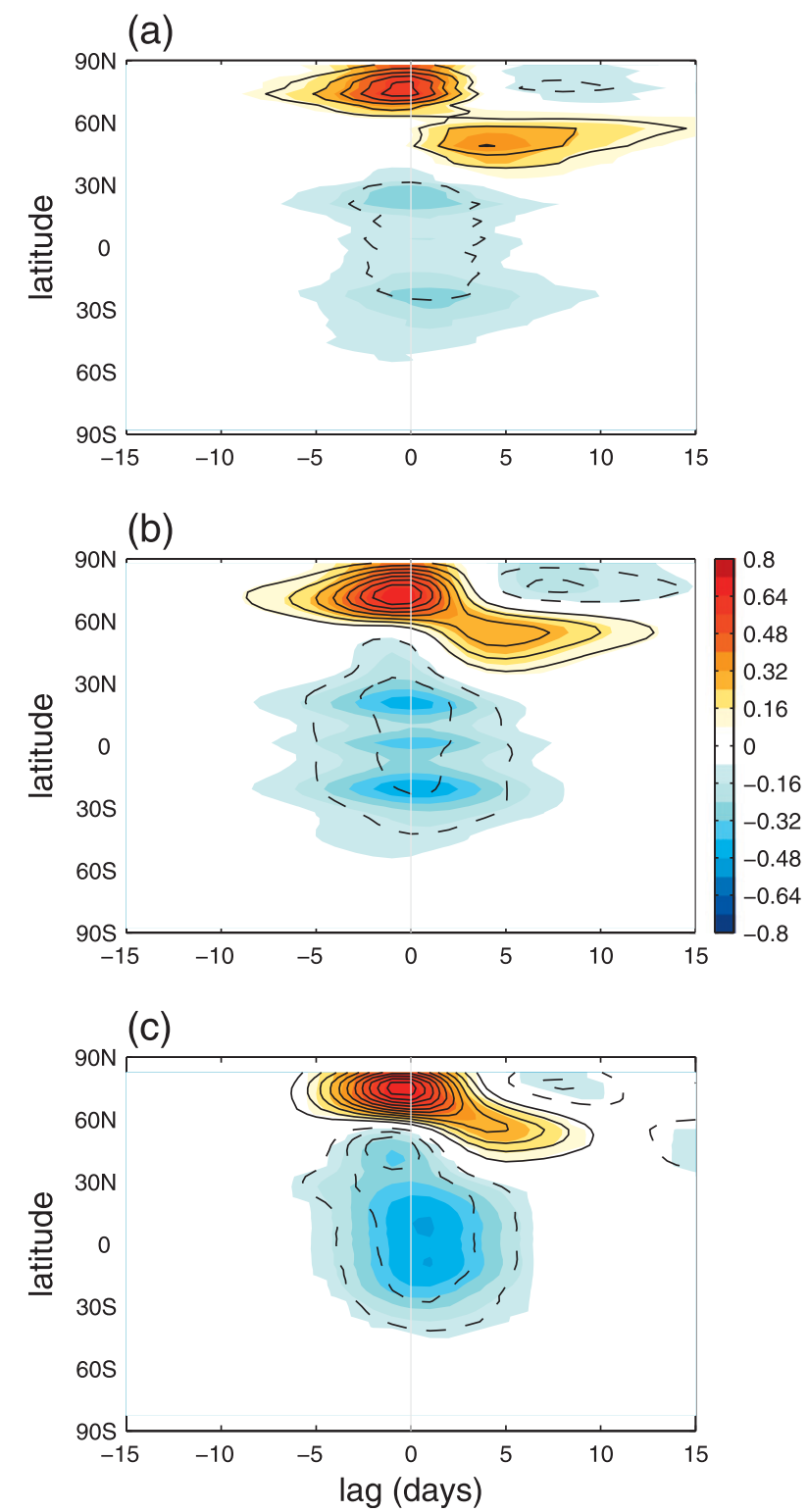

FIG. 3. (a) Latitudinal profile of $\omega^{*}$ at the 65 -hPa level correlated with (color) and regressed upon (contours; $2 \mathrm{~Pa} \mathrm{day}^{-1}$ ) the daily time series of $100-\mathrm{hPa}\left[v^{\prime} T^{\prime}\right]$ averaged over $45^{\circ}-90^{\circ} \mathrm{N}$ at various lags based on model data. (b) As in (a), but correlations and regressions (contours; $10^{-2} \mathrm{~K} \mathrm{day}^{-1}$ ) of $65-\mathrm{hPa} \partial[T] / \partial t$ profile. (c) As in (b), but MSU-4 $\partial[T] / \partial t$ correlated with and regressed upon the daily time series of $100-\mathrm{hPa}\left[v^{\prime} T^{\prime}\right]$ averaged over $45^{\circ}-90^{\circ} \mathrm{N}$ based on ERA-Interim November-March data. Positive (negative) lags indicate $\omega^{*}$ and $\partial[T] / \partial t$ lagging (leading) the high-latitude $\left[v^{\prime} T^{\prime}\right]$ index. Solid (dashed) contours represent positive (negative) regression coefficients weighted by the cosine of latitude. Correlation coefficients are significant at the $99 \%$ level.

$\partial[T] / \partial t$ field is significantly correlated with the highlatitude $\left[v^{\prime} T^{\prime}\right]$ at lags ranging from day -4 to +4 , reflecting the persistence of the eddy heat flux anomalies. Hence, the approximately 10-day time scale of the 
(a)
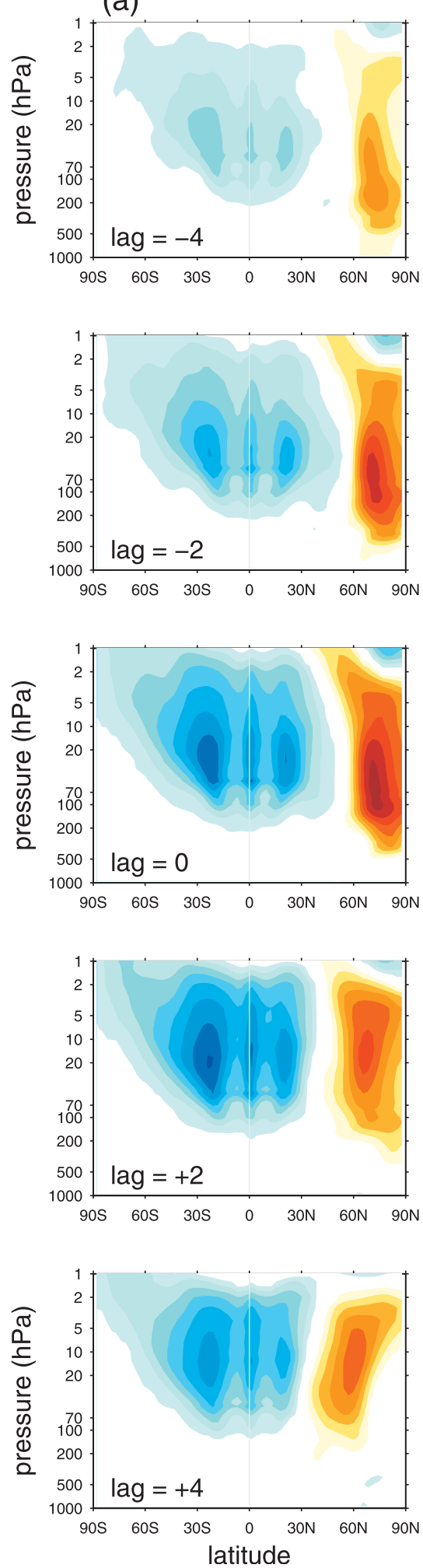

(b)
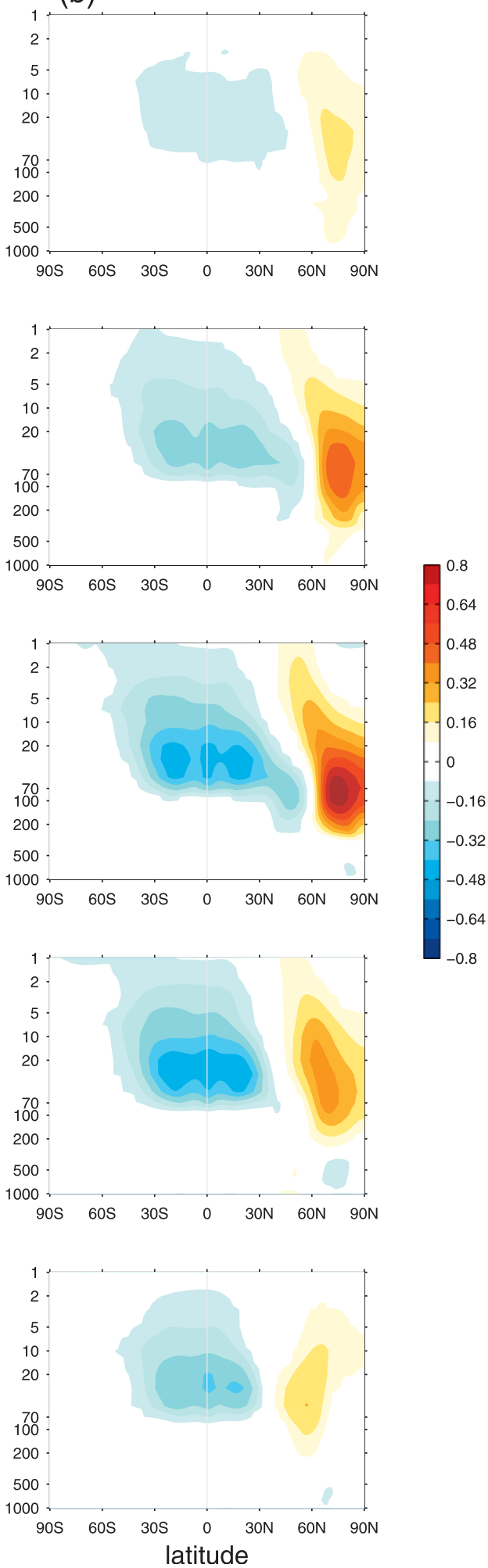

FIG. 4. The $\partial[T] / \partial t$ field correlated with the daily time series of $100-\mathrm{hPa}\left[v^{\prime} T^{\prime}\right]$ averaged over $45^{\circ}-$ $90^{\circ} \mathrm{N}$ at $-4-,-2-, 0-,+2-$, and +4-day lags based on 3-day Lanczos low-pass filtered (a) model and (b) ERA-Interim November-March data. Positive (negative) lags indicate the $\partial[T] / \partial t$ field lagging (leading) the high-latitude $\left[v^{\prime} T^{\prime}\right]$ index. Correlation coefficients are significant at the $99 \%$ level. 
(a)

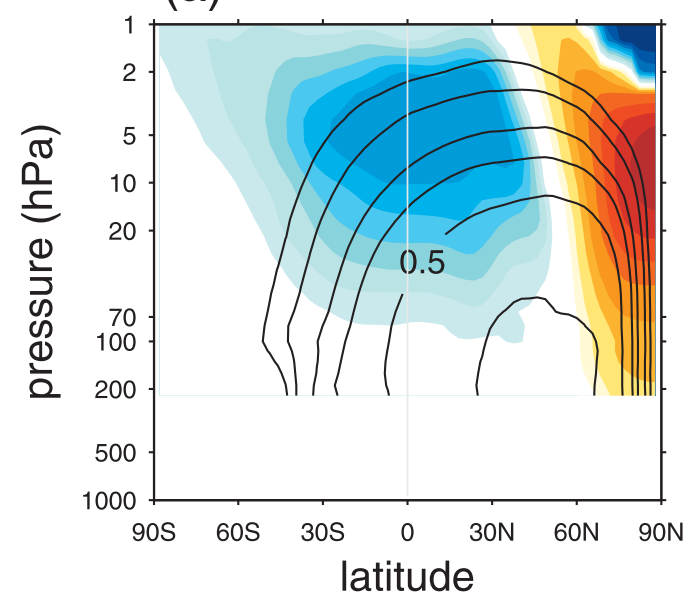

(b)

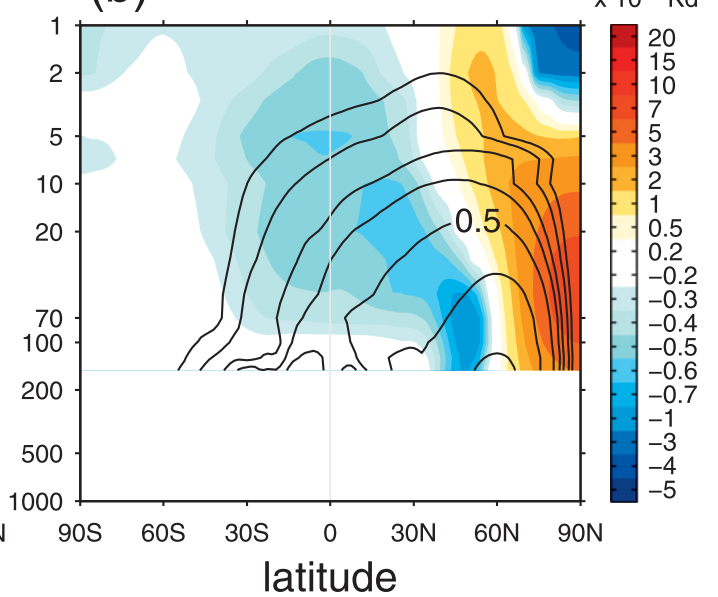

FIG. 5. Vertical cross sections of $\partial[T] / \partial t$ (color) and $\psi^{*}$ (contours; $\pm 0.05,0.1,0.2,0.3,0.5,1,2 \times 10^{9} \mathrm{~kg} \mathrm{~s}^{-1}$ ) fields regressed upon the daily time series of $100-\mathrm{hPa}\left[v^{\prime} T^{\prime}\right]$ averaged over $45^{\circ}-90^{\circ} \mathrm{N}$ based on (a) model and (b) ERAInterim November-March data. Solid contours represent positive streamfunction values, indicating clockwise circulation.

tropical upwelling anomalies inferred from Figs. 2 and 3 is set by the characteristic time scale of the modulations in the intensity of the planetary Rossby waves. Tropical cooling and polar warming first become evident at day -4 . The correlations become stronger in subsequent days with very little modulation of their spatial structures. The polar warming is strongest at day 0 and weakens thereafter. In ERA-Interim (Fig. 4b), the warming of the polar cap region is flanked by cooling at about $40^{\circ}-$ $60^{\circ} \mathrm{N}$ in the approximately $100-200-\mathrm{hPa}$ layer. This lobe of localized cooling is connected to a broader tropical cooling above about $70 \mathrm{hPa}$ that spreads across the equator into the $\mathrm{SH}$. The cooling of the entire tropical stratosphere peaks at day +2 in both the simulation and in ERA-Interim. The broad, equatorially symmetric cooling signature persists for more than 4 days, with somewhat stronger correlations between tropical $\partial[T] / \partial t$ and high-latitude $\left[v^{\prime} T^{\prime}\right]$ in the model than in ERAInterim. These results are qualitatively similar to the lagged composites of $[T]$ with respect to anomalously large upward EP fluxes shown in Fig. 6 of Karlsson et al. (2009) based on a comprehensive general circulation model.

Figure 5 confirms that variations in $\partial[T] / \partial t$ associated with high-latitude planetary wave propagation in Fig. 4 are driven by changes in the strength of the meridional circulation. The $\psi^{*}$ fields in the model and ERA-Interim are regressed upon the daily time series of the highlatitude $100-\mathrm{hPa}\left[v^{\prime} T^{\prime}\right]$ index. The TEM circulation exhibits a deep vertical structure with upwelling spreading across the equator into the $\mathrm{SH}$, particularly in the model. The overall shape of these patterns resembles the deep, upper branch of the climatological-mean boreal winter BDC in Fig. $1 \mathrm{~b}$ and the $\psi^{*}$ field regressed upon the daily time series of tropical $\left(30^{\circ} \mathrm{S}-30^{\circ} \mathrm{N}\right)$ lower-stratospheric $\partial[T] / \partial t$ (not shown). The 10-day Lanczos low-pass filtered daily time series of tropical $65-\mathrm{hPa} \partial[T] / \partial \mathrm{t}$ and high-latitude $100-\mathrm{hPa}\left[v^{\prime} T^{\prime}\right]$ are correlated at a level of -0.75 in the simulation. The corresponding correlations based on MSU-4 and ERA-Interim $\partial[T] / \partial t$ at $70-\mathrm{hPa}$ are slightly weaker $(-0.62$ and -0.51 , respectively; Table 1$)$, but still highly significant.

Note, however, that the correlation between highlatitude $100-\mathrm{hPa}\left[v^{\prime} T^{\prime}\right]$ and tropical $\partial[T] / \partial t$, shown in Figs. 4 and 5, drops off sharply with depth, from -0.51 at $70 \mathrm{hPa}$ to -0.24 at $100 \mathrm{hPa}$ in the reanalysis (Table 1 ). Figure 6 reveals the vertical structure of intraseasonal anomalies in the tropical upwelling. The ERA-Interim $\partial[T] / \partial t$ field is significantly correlated with MSU-4 tropical $\partial[T] / \partial t$ time series throughout the $20-70-\mathrm{hPa}$ layer, with a maximum correlation of about 0.6 at the $30-\mathrm{hPa}$ level, as shown in Fig. 6a. Hence, it is evident that MSU-4 samples temperatures over a deep layer in the stratosphere and that the intraseasonal variability in $\partial[T] / \partial t$ is relatively uniform within the $20-70$-hPa layer in ERA-Interim.

Figures $6 \mathrm{~b}$ and $6 \mathrm{c}$ show cross sections of $\partial[T] / \partial t$ correlated with and regressed upon tropical $\partial[T] / \partial t$ time series at the 50- and 100-hPa levels in ERA-Interim, respectively. By construction, intraseasonal variations in $\partial[T] / \partial t$ are highly correlated at the level of the tropical time series. Tropical $\partial[T] / \partial t$ variations at the $50-\mathrm{hPa}$ level are strongly correlated with tropical $\partial[T] / \partial t$ from 20- to 70-hPa levels, as evidenced by the deep 

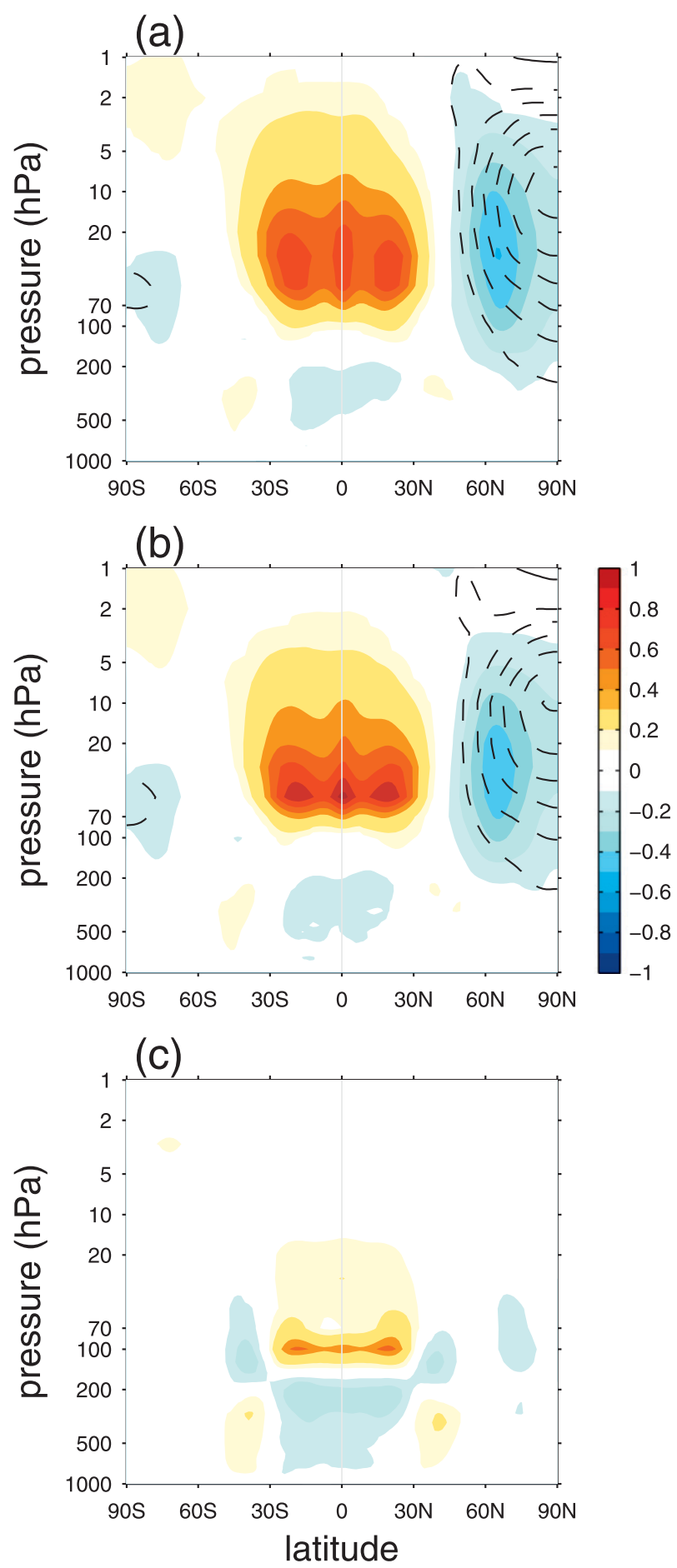

FIG. 6. (a) Vertical cross section of the ERA-Interim $\partial[T] / \partial t$ field correlated with (color) and regressed upon (contours; $0.1 \mathrm{~K} \mathrm{day}^{-1}$ ) the November-March daily time series of MSU-4 tropical $\left(30^{\circ} \mathrm{S}-\right.$ $\left.30^{\circ} \mathrm{N}\right) \partial[T] / \partial t$. (b), (c) As in (a), but correlated with and regressed upon the November-March daily time series of ERA-Interim tropical $\partial[T] / \partial t$ at $50-\mathrm{hPa}$ and $100-\mathrm{hPa}$ levels, respectively. Solid (dashed) contours represent positive (negative) regression coefficients. Correlation coefficients are significant at the $99 \%$ level. vertical extent of the shaded region in Fig. 6b. However, the correlations drop off rapidly with depth below $70 \mathrm{hPa}$. A similar result is obtained when the $\partial[T] / \partial t$ field is correlated with tropical $\partial[T] / \partial t$ time series at the $70-\mathrm{hPa}$ level (not shown). In contrast, the variability in tropical $\partial[T] / \partial t$ at the $100-\mathrm{hPa}$ level is localized and only weakly correlated with the variability at neighboring levels (Fig. 6c). Time series of tropical $\partial[T] / \partial t$ at the 70- and 100-hPa levels are weakly correlated $(r=0.38$; Table 1$)$.

In summary, the propagation of planetary waves into the high-latitude stratosphere can explain much of the high-frequency variability in tropical upwelling at about $70 \mathrm{hPa}$ and above, but it accounts for less of the variability of temperature of the tropical cold-point tropopause, which is situated closer to the $100-\mathrm{hPa}$ level. Variations in MSU-4 temperatures are more strongly correlated with ERA-Interim temperatures at $70 \mathrm{hPa}$ than at $100 \mathrm{hPa}(r=0.80$ versus 0.49 ; Table 1$)$ and thus reflect the variability of the upper branch of the BDC, which is forced mainly by planetary waves originating in high latitudes.

\section{b. Connecting high-latitude wave propagation to stratospheric wave driving}

To relate the upward propagation of high-latitude planetary waves through the $100-\mathrm{hPa}$ surface to the mechanical forcing of the stratosphere, we show in Fig. 7 series of meridional cross sections generated by correlating the divergence of the EP flux upon the highlatitude $100-\mathrm{hPa}\left[v^{\prime} T^{\prime}\right]$ index. The evolution of the EP flux divergence may be interpreted as tracing out the region of wave breaking or forcing. The sequence begins with wave forcing concentrated in the extratropical stratosphere poleward of $45^{\circ} \mathrm{N}$. By day +2 to +4 , nearly all the wave forcing in the model has shifted to the tropical and subtropical latitudes. The wave forcing in ERA-Interim is not as strong as in the model, as evidenced by the weaker correlations in Fig. 7b compared to those in Fig. 7a, but the evolution of the pattern is similar. At the time of peak wave propagation into the high-latitude stratosphere, EP flux divergence is maximum in the region poleward of $45^{\circ} \mathrm{N}$ above the $100-\mathrm{hPa}$ level. The region of wave forcing shifts equatorward with time so that by day +2 most of the wave breaking occurs in the subtropical stratosphere. By day +4 , all remnants of the high-latitude wave breaking have completely disappeared, but wave breaking in the subtropics is still clearly evident.

While the overall structure and evolution of the EP flux divergence field in ERA-Interim resemble those in the model, the variability of the low-latitude EP fluxes in ERA-Interim is not as strong. The EP fluxes in the model extend nearly all the way to the equator, whereas 
(a)
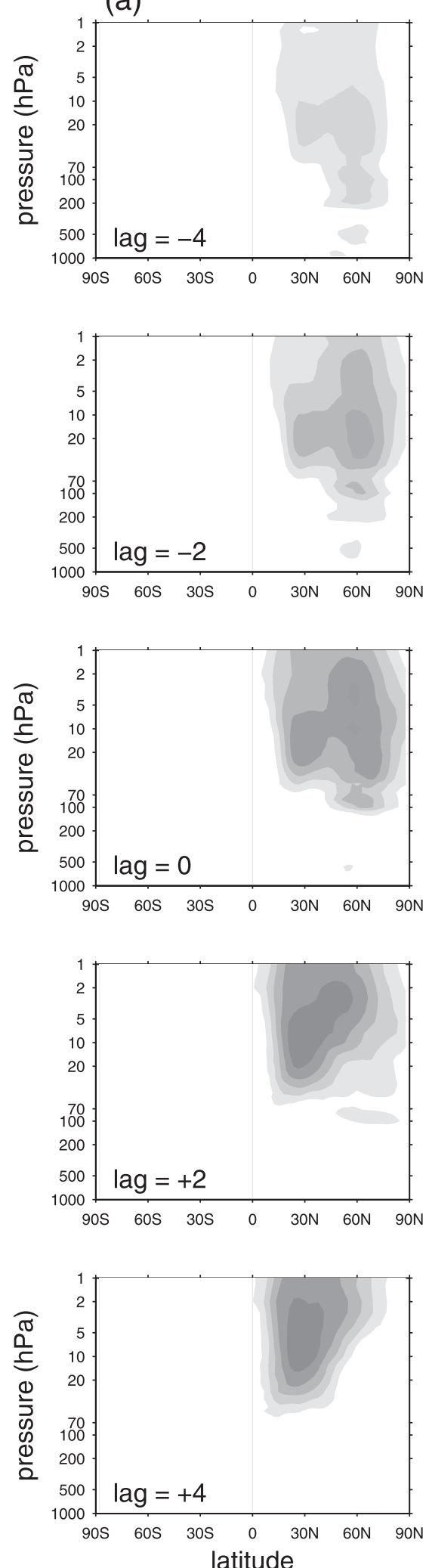

(b)
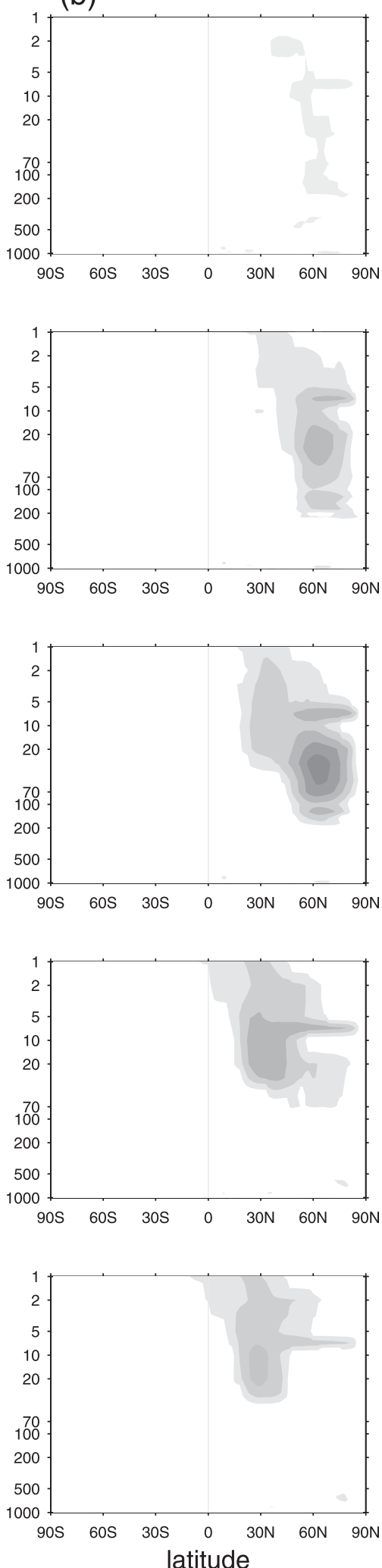

FIG. 7. As in Fig. 4, but for the EP flux divergence field. Positive (negative) lags indicate the EP flux divergence field lagging (leading) the high-latitude $\left[v^{\prime} T^{\prime}\right]$ index. Correlation coefficients are significant at the $99 \%$ level. 
in the ERA-Interim they extend only as far as about $20^{\circ} \mathrm{N}$. It is possible that the data assimilation corrections in the reanalysis are overwhelming the weak EP flux divergence perturbations in the tropics.

The sequence of patterns in Figs. 4 and 7 suggests that the tropical response to bursts of high-latitude planetary wave activity proceeds in two stages. In the early stage, tropical cooling appears as a remote, nearly simultaneous response to wave breaking in the high latitudes, consistent with the notion of sideways control (Holton et al. 1995). On time scales shorter than the radiative relaxation time scale, highlighted in Figs. 2-6, wave breaking in the high latitudes alone can drive transient modulations of tropical upwelling.

In the later stage, wave breaking shifts to low latitudes, where it is capable of both driving transient, highfrequency variations in tropical upwelling and contributing to the forcing of time-mean tropical upwelling in the upper branch of the BDC. This low-latitude tail of wave-breaking events is necessary for driving tropical upwelling on time scales sufficiently longer than the radiative relaxation time scale, when downward control becomes applicable.

The spreading of the wave-forcing region across much of the hemisphere on a time scale of days, however, suggests that a distinction between high- and lowlatitude wave breaking associated with real planetary waves may be somewhat artificial. Planetary waves originating in the extratropics are associated with a very broad pattern of wave breaking, as documented by McIntyre and Palmer (1983) and illustrated here in Fig. 7.

\section{c. Variability on monthly and seasonal time scales}

Ueyama and Wallace (2010, hereafter UW) showed evidence of strong coupling between high-latitude planetary wave activity, as represented by the eddy heat flux averaged over $50^{\circ}-80^{\circ} \mathrm{N} / \mathrm{S}$ and $10-50 \mathrm{hPa}$, and the $\mathrm{BDC}$, as represented by the leading PC time series of the equatorially symmetric component of the pole-to-pole meridional profile of $[T]^{*}$ based on MSU-4 data. Positive values of the PC, which are associated with below normal temperatures in the tropics and above normal temperatures poleward of $40^{\circ}$ latitude, are indicative of an intensification of the BDC and vice versa. To represent the variability on time scales longer than the radiative relaxation time scale, they employed a low-pass filter comprising successive, centered 5- and 3-monthrunning-mean smoothing operators. Their Fig. 12b shows a strong correspondence between the low-pass filtered eddy heat flux and PC time series, and their Fig. 13 and Table $2 \mathrm{c}$ corroborate this result. UW were unable to reconcile the apparent forcing of the BDC by the high-latitude planetary waves with the downward control principle at the low frequencies because the planetary wave forcing that they identified did not appear to extend into the tropics.

In section $4 \mathrm{~b}$, we showed that on 10-day time scales, EP fluxes associated with the high-latitude planetary waves do, indeed, extend deep into the tropics. This confirms that tongues of high potential vorticity air routinely stretch into the subtropics, as depicted in the single wave-breaking episode shown in Fig. 2 of McIntyre and Palmer (1983). To capture the impact of this wave breaking on longer time scales, we first show in Fig. 8 pole-to-pole time-latitude sections of 90-day Lanczos low-pass filtered $\left[v^{\prime} T^{\prime}\right]$ averaged over the 10 100-hPa layer superimposed on the 2-65-hPa fields of $\omega^{*}$ and $[T]^{*}$, a low-frequency analog to Figs. 2a,b. On this seasonal time scale, the meridional structure of the $\omega^{*}$ and $[T]^{*}$ perturbations is indicative of an enhancement of the BDC when the high-latitude heat fluxes are anomalously strong and vice versa. The low-frequency cutoff of the Lanczos filter is not low enough to completely eliminate the phase lag between $\omega^{*}$ and $[T]^{*}$. The high-latitude $\left[v^{\prime} T^{\prime}\right]$ in Fig. 8 may be interpreted as the effect of the episodic incursions of planetary wave activity into the tropics, as described in the previous section.

Consistent with the results presented in UW, tropical $\omega^{*}$ and $[T]^{*}$ averaged from 1 to $70 \mathrm{hPa}$ in ERA-Interim are also significantly correlated with high-latitude $\left[v^{\prime} T^{\prime}\right]$, as shown in Table 2. However, it is notable that this strong coupling does not extend downward to $100-\mathrm{hPa}$, near the level of the tropical cold-point tropopause.

Figure 9 establishes the connection between lowfrequency anomalies in high-latitude eddy heat fluxes, stratospheric temperatures, and the residual mean circulation. We repeat the analysis shown in Fig. 5, but substitute $[T]^{*}$ for $\partial[T] / \partial t$, in order to represent the phase relationships at low frequencies. The high-latitude wave index in this section is defined as the deviations of $\left[v^{\prime} T^{\prime}\right]$ from climatology, integrated from 10 to $100 \mathrm{hPa}$ and from $45^{\circ}$ to $90^{\circ} \mathrm{N}$. Figures $9 \mathrm{a}, \mathrm{b}$ show monthly (or 30-day) mean $\psi^{*}$ and $[T]^{*}$ anomalies regressed on the high-latitude $\left[v^{\prime} T^{\prime}\right]$ index. Figures $9 \mathrm{c}, \mathrm{d}$ show the same relationships, but now based on 3-month Lanczos lowpass filtered fields. The downward control becomes more applicable on these longer time scales, but the regressions become noisier, particularly at lower levels, as a result of the reduction in the number of temporal degrees of freedom.

On both monthly and seasonal time scales, we observe a connection between wave activity in the high latitudes and widespread cooling of the tropical stratosphere and warming of the polar stratosphere, particularly at upper 
(a)
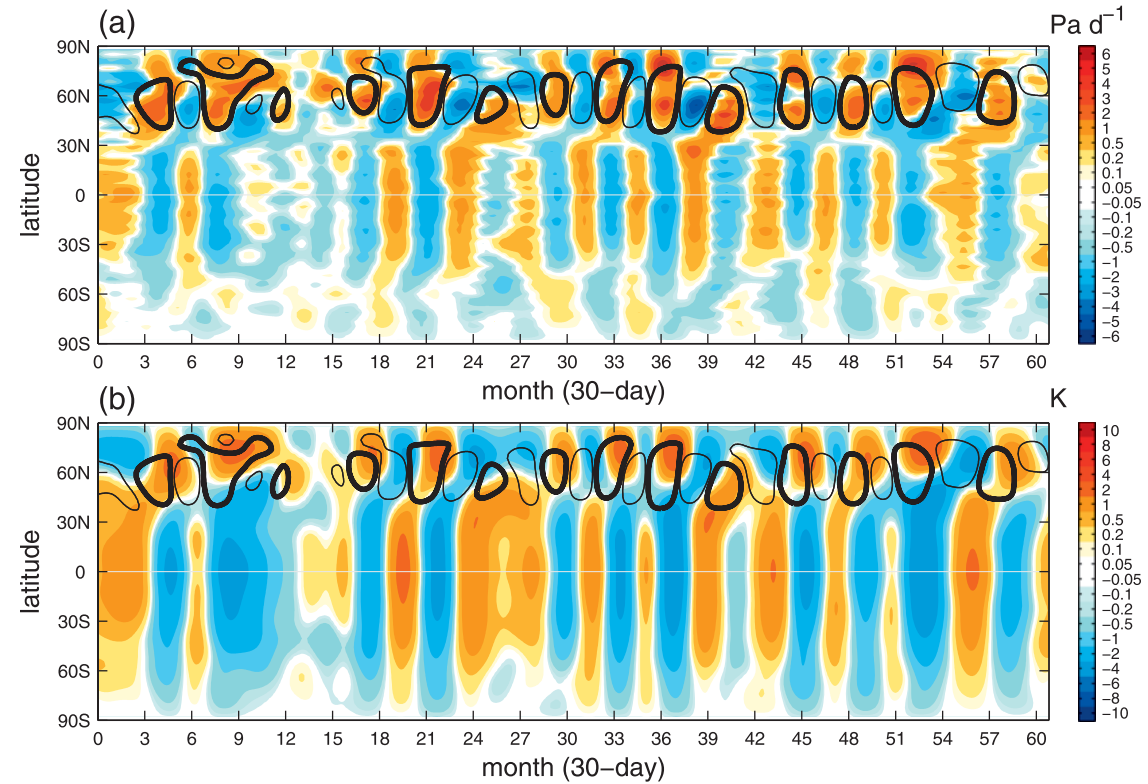

FIG. 8. Time-latitude sections of the $2-65-\mathrm{hPa}$ (a) $\omega^{*}$ and (b) $[T]^{*}$ (i.e., local $[T]$ minus the global mean $[T]$ at each level) based on 90-day Lanczos low-pass filtered model data. The $10-100-\mathrm{hPa}$ eddy heat fluxes $\left[v^{\prime} T^{\prime}\right]$ greater than $2 \mathrm{~m} \mathrm{~s}^{-1} \mathrm{~K}$ (less than $-2 \mathrm{~m} \mathrm{~s}^{-1} \mathrm{~K}$ ) during the same time period are plotted in thick (thin) black contours in the NH. The sign of $\left[v^{\prime} T^{\prime}\right]$ is reversed in the SH such that positive $\left[v^{\prime} T^{\prime}\right]$ (thick contours) indicate poleward eddy heat fluxes in both hemispheres. All fields are weighted by the cosine of latitude.

levels between 2 and $20 \mathrm{hPa}$. The $\psi^{*}$ regressions confirm that these temperature anomalies are driven by an increase in the strength of the upper branch of the BDC. The agreement between the model and reanalysis is better on these lower frequencies than on the higher frequencies.

Figure 9 also reflects the inability of the planetary waves originating in high latitudes to explain variations in temperature in the lower branch of the BDC. The regression of tropical temperatures approaches zero just below $70 \mathrm{hPa}$ in ERA-Interim (Figs. 9b,d). Seasonalmean time series of tropical $[T]^{*}$ averaged over 1$70 \mathrm{hPa}$ is only weakly correlated with tropical $[T]^{*}$ at $100 \mathrm{hPa}(r=0.14$; Table 2$)$, suggesting that variability of the upper branch of the BDC is largely disconnected from the variability of the lower branch on a broad range of time scales.

\section{Forcing of the variability below $70 \mathrm{hPa}$}

The structure of the TEM circulation that influences the variability in tropical upwelling at $70-$ and $100-\mathrm{hPa}$ levels is investigated further by performing a onedimensional EOF analysis of 10-, 30-, and 90-day Lanczos low-pass filtered $\psi^{*}$ at specified pressure levels. We focus on ERA-Interim data only, given the bias in the model's tropical tropopause height.

The pattern obtained by regressing the $\psi^{*}$ field upon the leading $\mathrm{PC}$ time series derived from EOF analysis of $\psi^{*}$ at the 70-hPa level is shown in the top row of Fig. 10.

TABLE 2. Correlation coefficients between 3-month Lanczos low-pass filtered monthly time series (ERA-Interim, November-March 1979-2010): high-latitude $\left(45^{\circ}-90^{\circ} \mathrm{N}\right)\left[v^{\prime} T^{\prime}\right]$ at $10-100 \mathrm{hPa}$, tropical $\left(30^{\circ} \mathrm{S}-30^{\circ} \mathrm{N}\right) \omega^{*}$ at $1-70 \mathrm{hPa}$, tropical $\left(30^{\circ} \mathrm{S}-30^{\circ} \mathrm{N}\right)[T]^{*}$ at $1-70-$ and 100 -hPa levels. Quasi-biennial oscillation was removed from the monthly time series following the method described in section 2. Correlations that are not statistically significant at the $99 \%$ level are italicized.

\begin{tabular}{|c|c|c|c|c|}
\hline & $\begin{array}{c}\text { High-latitude }\left[v^{\prime} T^{\prime}\right] \text { at } \\
10-100 \mathrm{hPa}\end{array}$ & $\begin{array}{c}\text { Tropical } \omega^{*} \text { at } \\
1-70 \mathrm{hPa}\end{array}$ & $\begin{array}{c}\text { Tropical }[T]^{*} \text { at } \\
1-70 \mathrm{hPa}\end{array}$ & $\begin{array}{c}\text { Tropical }[T]^{*} \text { at } \\
100 \mathrm{hPa}\end{array}$ \\
\hline High-latitude $\left[v^{\prime} T^{\prime}\right]$ at $10-100 \mathrm{hPa}$ & 1 & -0.66 & -0.69 & -0.07 \\
\hline Tropical $\omega^{*}$ at $1-70 \mathrm{hPa}$ & & 1 & 0.57 & 0.22 \\
\hline Tropical $[T]^{*}$ at $1-70 \mathrm{hPa}$ & & & 1 & 0.14 \\
\hline Tropical $[T] *$ at $100 \mathrm{hPa}$ & & & & 1 \\
\hline
\end{tabular}


(a)

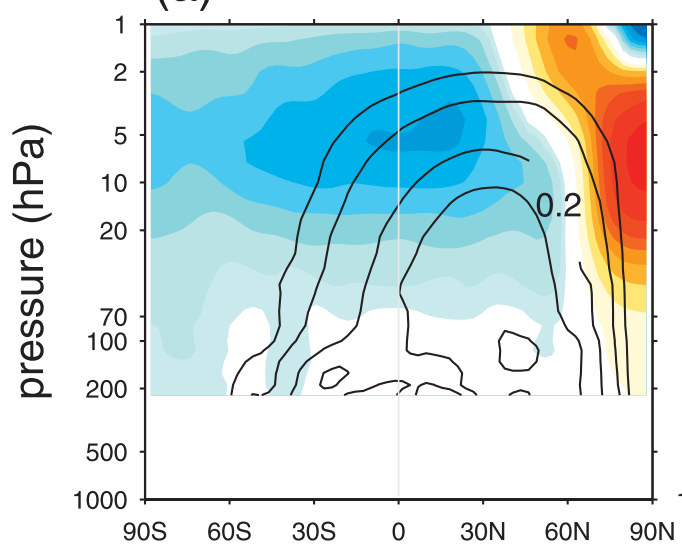

(c)

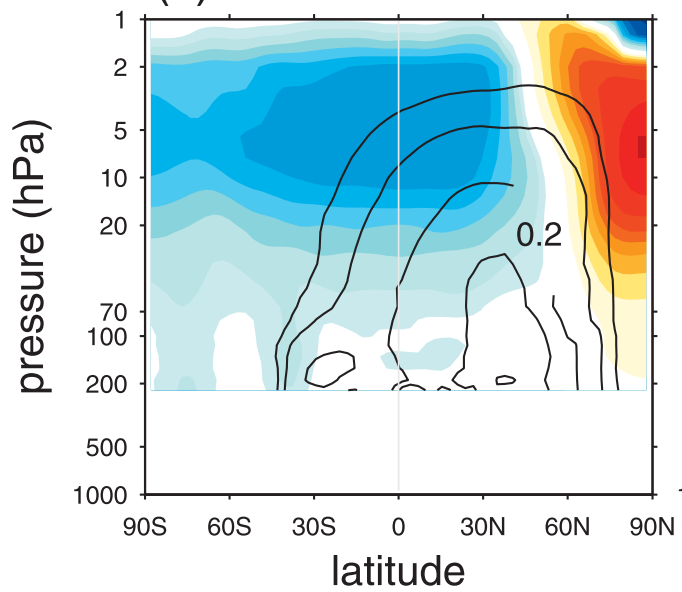

(b)

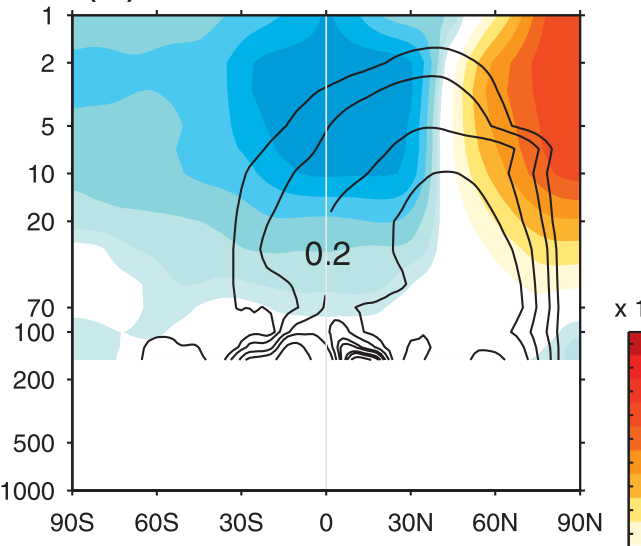

(d)

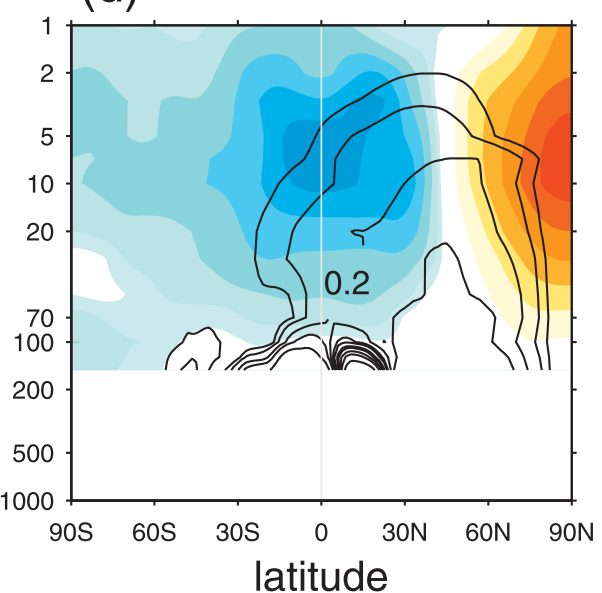

FIG. 9. Vertical cross sections of the $[T]^{*}$ (color) and $\psi^{*}$ (contours; $\pm 0.05,0.1,0.2,0.3,0.5,1,2 \times 10^{9} \mathrm{~kg} \mathrm{~s}^{-1}$ ) fields regressed upon the time series of $\left[v^{\prime} T^{\prime}\right]$ averaged over $45^{\circ}-90^{\circ} \mathrm{N}$ and $10-100 \mathrm{hPa}$ based on (a) monthly (30-day mean) model and (b) ERA-Interim November-March data. (c),(d) As in (a),(b), respectively, but based on seasonal (3-month Lanczos low-pass filtered) data. Solid contours represent positive streamfunction values, indicating clockwise circulation.

The TEM circulation pattern for each frequency band resembles the deep, equator-to-pole BDC associated with variations in high-latitude $\left[v^{\prime} T^{\prime}\right]$ as seen in Figs. $5 b$, $9 \mathrm{~b}$, and $9 \mathrm{~d}$, respectively. This mode explains roughly $50 \%$ of the intraseasonal variability in $\psi^{*}$ irrespective of the low-pass cutoff of the filter. The leading EOF of $\psi^{*}$ at the 100-hPa level, shown in the middle row of Fig. 10, consists of a shallower equator-to-pole circulation that is mainly confined in the lower stratosphere. At lower frequencies, the cell becomes even more meridionally confined and the descending branch shifts to lower latitudes. The tropical cell below $70 \mathrm{hPa}$, with ascent in the equatorial belt and subsidence in the outer tropics, resembles the structure of the residual circulation forced by equatorial planetary waves (e.g., Norton 2006; Deckert and Dameris 2008). A deeper mode that resembles the leading EOF of $\psi^{*}$ at $70 \mathrm{hPa}$ appears as the third mode in the 100-hPa EOF expansions, shown in the bottom row of Fig. 10. PC 3 of $\psi^{*}$ at $100 \mathrm{hPa}$ is well correlated with PC 1 of $\psi^{*}$ at $70 \mathrm{hPa}$ at $r=0.88,0.83$, and 0.81 for $10-, 30-$, and 90 -day low-pass filtered data, respectively. However, for time scales of 10 days and longer, only $13 \%$ of the variance is associated with this deep mode, while this mode explains only $8 \%$ of the variance on time scales 90 days and longer. Thus we conclude that the variability of the upper branch of the BDC with upwelling at $70 \mathrm{hPa}$ and above makes only a small contribution to the variability of the upwelling at the tropical cold point near $100 \mathrm{hPa}$.

The results of the EOF analysis support our conclusion that the influence of the variations in the upper branch of the BDC, driven by the breaking of 
(a) 10-day

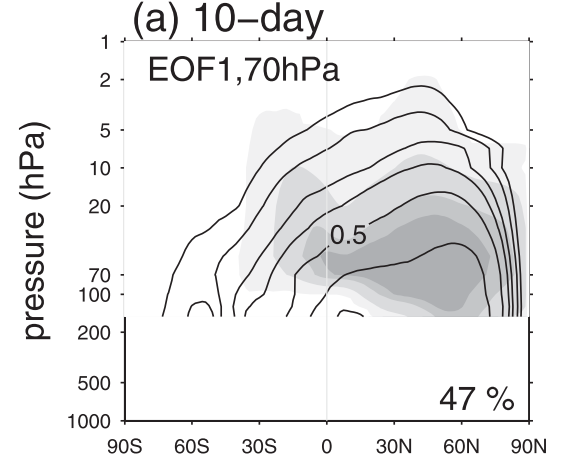

(b) 30-day
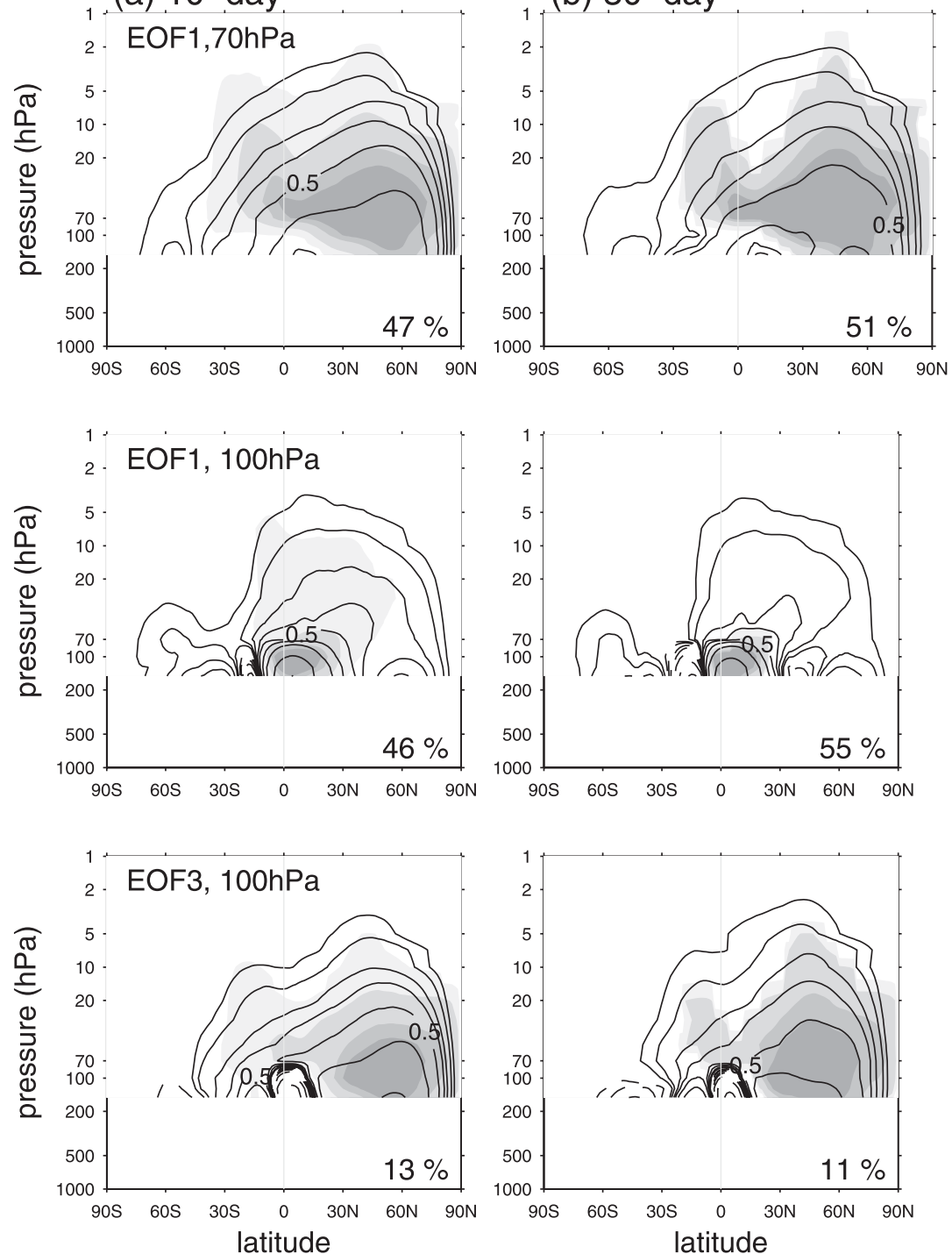
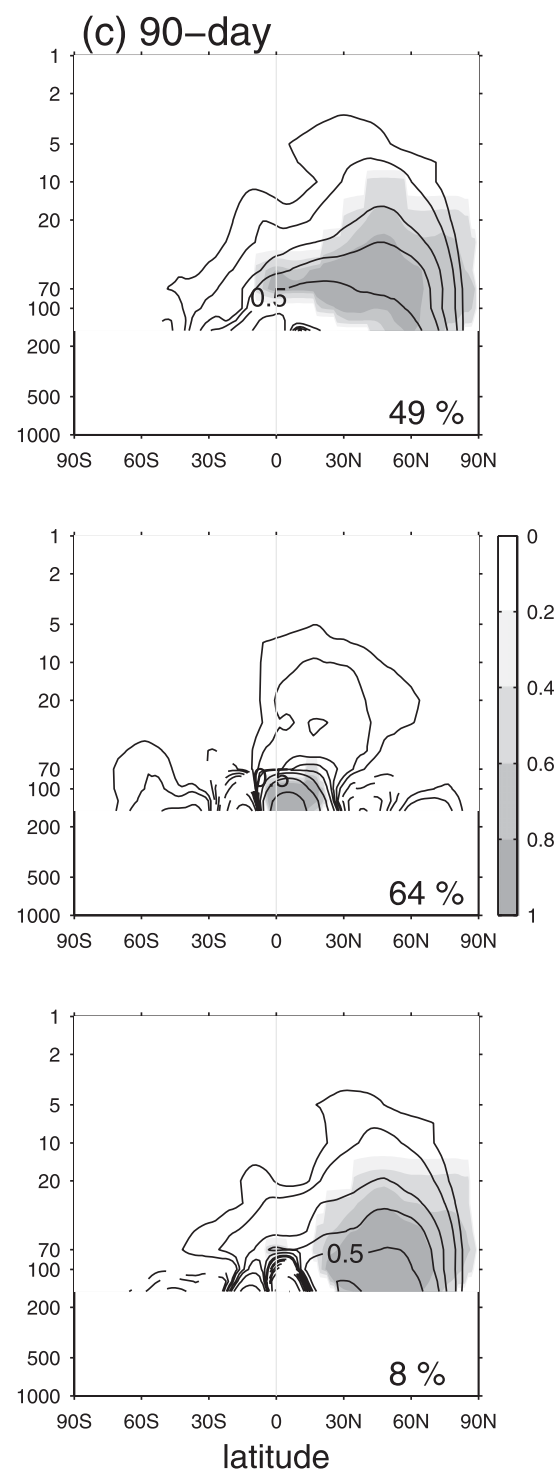

FIG. 10. (a) Vertical cross sections of the $\psi^{*}$ field correlated with (gray shading) and regressed upon (contours; $\pm 0.05,0.1,0.2,0.3,0.5,1$, $2 \times 10^{9} \mathrm{~kg} \mathrm{~s}^{-1}$ ) the standardized leading PC time series computed from EOF analysis of $\psi^{*}$ from pole to pole at (top) 70- and (middle) 100-hPa levels based on 10-day Lanczos low-pass filtered ERA-Interim November-March data. (bottom) As in (top), but correlated with and regressed upon PC 3 of $\psi^{*}$ at $100 \mathrm{hPa}$. (b),(c) As in (a), but based on 30-day and 90-day Lanczos low-pass filtered data, respectively. Correlation coefficients are significant at the $99 \%$ level. The percentage of variance explained by each mode is shown in the bottom-right corner of each panel.

planetary waves originating in high latitudes, declines rapidly with depth below $70 \mathrm{hPa}$. The reduction in the variance by roughly a factor of 3-6 is consistent with the sharp gradient in the mass transport between 70 and $100-\mathrm{hPa}$ levels: recall that only about $1 / 5$ of the mass that upwells through the $100-\mathrm{hPa}$ surface between $15^{\circ} \mathrm{S}$ and $15^{\circ} \mathrm{N}$ reaches the $70-\mathrm{hPa}$ level. Hence wave breaking above $70 \mathrm{hPa}$, the primary driver of the upper branch of the BDC, can only have a limited impact on the upwelling at $100-\mathrm{hPa}$ in comparison to the wave forcing in the lower stratosphere between 70- and 100-hPa levels.

\section{Summary of findings and discussion}

We have investigated the forcing of the tropical upwelling in the Brewer-Dobson circulation (BDC) based on the analysis of perpetual-January integrations of an idealized general circulation model and November-March data of the ERA-Interim and MSU-4 measurements of 
lower-stratospheric temperature. Our main findings are as follows:

1. Nonseasonal variability of the BDC is dominated by time scales of about 10 days, consistent with the time scale of high-latitude planetary waves. Enhanced poleward eddy heat fluxes $\left[v^{\prime} T^{\prime}\right]$ in the high latitudes $\left(45^{\circ}-90^{\circ} \mathrm{N}\right)$ at the $100-\mathrm{hPa}$ level are associated with nearly instantaneous anomalous tropical cooling (i.e., negative $\partial[T] / \partial t$ ) above the 70-hPa level and anomalous warming (i.e., positive $\partial[T] / \partial t$ ) on the poleward side of the polar night jet (Figs. 2-5), suggestive of an episodic strengthening of the BDC driven by the breaking of high-latitude wintertime planetary waves or "sideways control."

2. Lag-lead correlations of the EP flux divergence field with high-latitude wave propagation, as represented by an index of the $100-\mathrm{hPa}\left[v^{\prime} T^{\prime}\right]$ poleward of $45^{\circ} \mathrm{N}$, illustrate the equatorward propagation of waves from the high latitudes to the subtropical and tropical stratosphere over a period of about 10 days (Fig. 7). Planetary waves originating in high latitudes give rise to a region of wave breaking extending from the pole to the tropics, consistent with a broad surf zone discussed in earlier works (e.g., Andrews et al. 1987). The equatorward propagation is more prominent in the model than in the reanalysis.

3. Averaged over a season or longer, the presence of planetary waves originating in high latitudes and breaking in the tropics contributes substantially to the forcing of the BDC. We propose that it is through this mechanism that the episodic, short-lived events analyzed in this study contribute to the pronounced annual cycle in the strength of the BDC as well as the nonseasonal variability on 90-day and longer time scales. In agreement with this hypothesis, a significant correlation is observed between wave activity in the high-latitude stratosphere and tropical $[T]^{*}$ in the upper branch of the BDC in the 90-day low-pass filtered data (Figs. 8 and 9). We have also found that the meridional profile of the time-mean, vertically integrated wave forcing at $70 \mathrm{hPa}$ (not shown) closely resembles the regression pattern at day +2 in Fig. 7. Short-lived events can have long-term effects on the BDC because, in both the simulation and in the reanalysis, the breaking of the high-latitude planetary waves occurs at sufficiently low latitudes to induce tropical upwelling by downward control.

4. The influence of planetary waves originating in high latitudes upon the strength of the tropical upwelling diminishes rapidly with depth below $70 \mathrm{hPa}$. Nonseasonal variations in tropical $\partial[T] / \partial t$ and $[T]^{*}$ at $100 \mathrm{hPa}$ are not strongly correlated with those at
$70 \mathrm{hPa}$ and above or with the high-latitude $\left[v^{\prime} T^{\prime}\right]$ index (Tables 1,2).

There are several factors that have led to different conclusions in prior studies regarding the role of highlatitude planetary waves in forcing the variability in the tropical upwelling:

- Zhou et al. (2012) showed that low-latitude EP fluxes computed on the basis of 6-hourly ERA-Interim data are substantially larger than those inferred by UW from the eddy fluxes of heat and zonal momentum calculated from pentad (5 day)-mean ERA-40 data. Not only are the EP fluxes in Zhou et al. (2012) a more direct measure of the wave forcing than the eddy fluxes in UW, but breaking planetary waves emanating from high latitudes may also include features that would not be resolvable in pentad-mean data.

- Even in the 6-hourly fields of ERA-Interim, features associated with low-latitude planetary wave breaking may be obscured by the data assimilation cycle, in which dynamical consistency is continually being sacrificed for the sake of updating the analysis with new observations. In this respect, the results based on numerical simulations presented in Fig. 7 of this study may well provide a more reliable indication of the amplitude of the low-latitude eddy forcing than the results based on "observations."

- The impact of the wave forcing on the tropical upwelling is inversely proportional to the Coriolis parameter. Hence, the smallness of the low-latitude fluxes belies their dynamical significance. Our use of correlation coefficients in this study places greater emphasis on the low-latitude fluxes than the use of regression coefficients in UW.

- The relative importance of high-latitude planetary waves in forcing the variability of tropical upwelling in the BDC depends on the level at which the upwelling is evaluated. The column-averaged tropical temperatures between 10 and $100 \mathrm{hPa}$ analyzed by Salby and Callaghan (2002) and the zonally averaged temperature profiles from MSU-4 analyzed in UW emphasize the vertical velocities in the upper branch of the BDC, which explains why these studies found strong correlations between variations in tropical upwelling and high-latitude planetary wave activity. In contrast, an appreciable contribution by low-latitude wave forcing was found in studies that examined the residual-mean vertical velocities near the $100-\mathrm{hPa}$ level, which are more strongly influenced by the lower branch of the BDC; for example, at 13-17 km (90$180 \mathrm{hPa}$ ) in Boehm and Lee (2003), $9 \mathrm{hPa}$ in KerrMunslow and Norton (2006), $100 \mathrm{hPa}$ in Randel et al. (2008), and $100 \mathrm{hPa}$ in Garny et al. (2011). 
An analysis of the mean age of air in the model by Gerber (2012) confirms the existence of a qualitative change in the character of the circulation, which occurs near $100 \mathrm{hPa}$ in the model. He found that the rapid decay of the strength of the TEM circulation with height in the lower stratosphere results in a sharp gradient in the mean age of air, while much older air with a more uniform age prevails at higher levels where the strength of the circulation decays more slowly with height. These results support the two-branch model of the BDC discussed in section 1 and are also consistent with the vertical structure of the amplitudes of the annual cycle in tropical lower-stratospheric temperature, shown in Fig. 1 of Reed and Vlcek (1969). The amplitude peaks near $80 \mathrm{hPa}$, presumably because of the strong tropical upwelling of the upper branch of the BDC during boreal winter in conjunction with the long radiative relaxation time scale at that level. The amplitude of the annual cycle diminishes rapidly with depth below about $80 \mathrm{hPa}$, reflecting the weaker seasonality in the strength of the lower branch and the shorter radiative relaxation time scale at $100 \mathrm{hPa}$ relative to $80 \mathrm{hPa}$.

This study clarifies the role of high-latitude wintertime planetary-scale waves in forcing the variability in the strength of the BDC on time scales longer than the radiative relaxation time scale of the lower stratosphere. The contribution by these waves to stratospheric wave driving has been well recognized since the early studies of Dunkerton et al. (1981) and McIntyre and Palmer (1983). However, the forcing of the tropical upwelling by these high-latitude waves on seasonal (and longer) time scales has not been widely appreciated, as evidenced by the numerous papers cited in section 1 that have sought alternative explanations for the observed annual cycle and low-frequency nonseasonal variability in the lower stratosphere. High-latitude planetary waves have been acknowledged as being important for driving high-frequency variations in upwelling in the tropical lower stratosphere by sideways control, but here we have presented modeling and observational results that suggest that they force the BDC by downward control as well. To what extent the seasonally varying climatological mean and the interannual variability of tropical upwelling at $70 \mathrm{hPa}$ and above are forced by waves originating in high and low latitudes remains to be seen.

Acknowledgments. MSU/AMSU data are produced by Remote Sensing Systems and sponsored by the NOAA Climate and Global Change Program. We thank two anonymous reviewers for their thoughtful comments and suggestions on the manuscript. This work was partially funded by NSF Climate Dynamics Program Office Grant 1122989 and the division of Atmospheric and Geospace Sciences Grants 0938325, 0846641, and 0936059; NASA Grant NNX09AH73G; and NOAA Grant NA08OAR4310725. R. Ueyama also thanks Dr. Leonhard Pfister and the NASA Postdoctoral Program for support.

\section{REFERENCES}

Andrews, D. G., and M. E. McIntyre, 1976: Planetary waves in horizontal and vertical shear: The generalized Eliassen-Palm relation and the mean zonal acceleration. J. Atmos. Sci., 33, 2031-2048.

_ Dynamics. Academic Press, 489 pp.

Birner, T., and H. Bönisch, 2011: Residual circulation trajectories and transit times into the extratropical lowermost stratosphere. Atmos. Chem. Phys., 11, 817-827.

Boehm, M. T., and S. Lee, 2003: The implications of tropical Rossby waves for tropical tropopause cirrus formation and for the equatorial upwelling of the Brewer-Dobson circulation. J. Atmos. Sci., 60, 247-261.

Bretherton, C. S., M. Widmann, V. P. Dymnikov, J. M. Wallace, and I. Bladé, 1999: The effective number of spatial degrees of freedom of a time-varying field. J. Climate, 12, 19902009.

Brewer, A. W., 1949: Evidence for a world circulation provided by the measurements of helium and water vapor distribution in the stratosphere. Quart. J. Roy. Meteor. Soc., 75, 351-363.

Chen, G., and L. Sun, 2011: Mechanisms of the tropical upwelling branch of the Brewer-Dobson circulation: The role of extratropical waves. J. Atmos. Sci., 68, 2878-2892.

Corti, T., B. P. Luo, and T. Peter, 2005: Mean radiative energy balance and vertical mass fluxes in the equatorial upper troposphere and lower stratosphere. Geophys. Res. Lett., 32, L06802, doi:10.1029/2004GL021889.

Deckert, R., and M. Dameris, 2008: Higher tropical SSTs strengthen the tropical upwelling via deep convection. Geophys. Res. Lett., 35, L10813, doi:10.1029/2008GL033719.

Dee, D. P., and Coauthors, 2011: The ERA-Interim Reanalysis: Configuration and performance of the data assimilation system. Quart. J. Roy. Meteor. Soc., 137, 553-597.

Dhomse, S., M. Weber, and J. Burrows, 2008: The relationship between tropospheric wave forcing and tropical lower stratospheric water vapor. Atmos. Chem. Phys., 8, 471-480.

Dobson, G. M. B., 1956: Origin and distribution of polyatomic molecules in the atmosphere. Proc. Roy. Soc. London, 236A, 187-193.

Dunkerton, T., C.-P. F. Hsu, and M. E. McIntyre, 1981: Some Eulerian and Lagrangian diagnostics for a model stratospheric warming. J. Atmos. Sci., 38, 819-843.

Edmon, H. J., Jr., B. J. Hoskins, and M. E. McIntyre, 1980: Eliassen-Palm cross sections for the troposphere. J. Atmos. Sci., 37, 2600-2616.

Fu, Q., Y. Hu, and Q. Yang, 2007: Identifying the top of the tropical tropopause layer from vertical mass flux analysis and CALIPSO lidar cloud observations. Geophys. Res. Lett., 34, L14813, doi:10.1029/2007GL030099.

Garcia, R. R., 1987: On the mean meridional circulation of the middle atmosphere. J. Atmos. Sci., 44, 3599-3609.

Garny, H., M. Dameris, W. Randel, G. E. Bodeker, and R. Deckert, 2011: Dynamically forced increase of tropical upwelling in the lower stratosphere. J. Atmos. Sci., 68, 12141233. 
Geller, M. A., T. Zhou, and K. Hamilton, 2008: Morphology of tropical upwelling in the lower stratosphere. J. Atmos. Sci., 65, 2360-2374.

Gerber, E. P., 2012: Stratospheric versus tropospheric control of the strength and structure of the Brewer-Dobson circulation. J. Atmos. Sci., 69, 2857-2877.

— , and L. M. Polvani, 2009: Stratosphere-troposphere coupling in a relatively simple AGCM: The importance of stratospheric variability. J. Climate, 22, 1920-1933.

Gettelman, A., P. M. de F. Forster, M. Fujiwara, Q. Fu, H. Vömel, L. K. Gohar, C. Johanson, and M. Ammerman, 2004: Radiation balance of the tropical tropopause layer. J. Geophys. Res., 109, D07103, doi:10.1029/2003JD004190.

Haynes, P. H., and M. E. McIntyre, 1987: On the evolution of vorticity and potential vorticity in the presence of diabatic heating and frictional and other forces. J. Atmos. Sci., 44, 828841.

— C. J. Marks, M. E. McIntyre, T. G. Shepherd, and K. P. Shine, 1991: On the "downward control" of extratropical diabatic circulations by eddy-induced mean zonal forces. J. Atmos. Sci., 48, 651-678.

Held, I. M., and B. J. Hoskins, 1985: Large-scale eddies and the general circulation of the troposphere. Advances in Geophysics, Vol. 28A, Academic Press, 3-31.

— , and M. J. Suarez, 1994: A proposal for the intercomparison of the dynamical cores of atmospheric general circulation models. Bull. Amer. Meteor. Soc., 75, 1825-1830.

Holton, J. R., 1990: On the global exchange of mass between the stratosphere and troposphere. J. Atmos. Sci., 47, 392-395.

— P. H. Haynes, M. E. McIntyre, A. R. Douglass, R. B. Rood, and L. Pfister, 1995: Stratosphere-troposphere exchange. Rev. Geophys., 33, 403-439.

Iwasaki, T., 1992: General circulation diagnosis in the pressureisentrope hybrid vertical coordinate. J. Meteor. Soc. Japan, 70, 673-687.

Karlsson, B., C. McLandress, and T. G. Shepherd, 2009: Interhemispheric mesospheric coupling in a comprehensive middle atmosphere model. J. Atmos. Sol.-Terr. Phys., 71, 518-530.

Kerr-Munslow, A. M., and W. A. Norton, 2006: Tropical wave driving of the annual cycle in tropical tropopause temperatures. Part I: ECMWF analyses. J. Atmos. Sci., 63, 1410-1419.

McIntyre, M. E., and T. N. Palmer, 1983: Breaking planetary waves in the stratosphere. Nature, 305, 593-610.

McLandress, C., and T. G. Shepherd, 2009: Simulated anthropogenic changes in the Brewer-Dobson circulation, including its extension to high latitudes. J. Climate, 22, 1516-1540.

Newman, P. A., and J. E. Rosenfield, 1997: Stratospheric thermal damping times. Geophys. Res. Lett., 24 (4), 433-436.

Norton, W. A., 2006: Tropical wave driving of the annual cycle in tropical tropopause temperatures. Part II: Model results. J. Atmos. Sci., 63, 1420-1431.

Plumb, R. A., 2002: Stratospheric transport. J. Meteor. Soc. Japan, 80, 793-809.

, and J. Eluszkiewicz, 1999: The Brewer-Dobson circulation: Dynamics of the tropical upwelling. J. Atmos. Sci., 56, 868890.
Polvani, L. M., and P. J. Kushner, 2002: Tropospheric response to stratospheric perturbations in a relatively simple general circulation model. Geophys. Res. Lett., 29 (7), doi:10.1029/ 2001 GL014284.

_- and D. W. Waugh, 2004: Upward wave activity flux as precursor to extreme stratospheric events and subsequent anomalous surface weather regimes. J. Climate, 17, 35483554.

Randel, W. J., R. Garcia, and F. Wu, 2002a: Time-dependent upwelling in the tropical lower stratosphere estimated from the zonal-mean momentum budget. J. Atmos. Sci., 59, 21412152.

— F. Wu, and R. Stolarski, 2002b: Changes in column ozone correlated with the stratospheric EP flux. J. Meteor. Soc Japan, 80, 849-862.

$\longrightarrow$, R. Garcia, and F. Wu, 2008: Dynamical balances and tropical stratospheric upwelling. J. Atmos. Sci., 65, 3584-3595.

Reed, R. J., and C. L. Vlcek, 1969: The annual temperature variation in the lower tropical stratosphere. J. Atmos. Sci., 26, 163167.

Rosenlof, K. H., 1995: Seasonal cycle of the residual mean meridional circulation in the stratosphere. J. Geophys. Res., 100 (D3), 5173-5191.

_ , and G. C. Reid, 2008: Trends in the temperature and water vapor content of the tropical lower stratosphere: Sea surface connection. J. Geophys. Res., 113, D06107, doi:10.1029/ 2007JD009109.

Ryu, J. H., and S. Lee, 2010: Effect of tropical waves on the tropical tropopause transition layer. J. Atmos. Sci., 67, 3130-3148.

Salby, M. L., and P. F. Callaghan, 2002: Interannual changes of the stratospheric circulation: Relationship to ozone and tropospheric structure. J. Climate, 15, 3673-3685.

Scott, R. K., 2002: Wave-driven mean tropical upwelling in the lower stratosphere. J. Atmos. Sci., 59, 2745-2759.

Semeniuk, K., and T. G. Shepherd, 2001: Mechanisms for tropical upwelling in the stratosphere. J. Atmos. Sci., 58, 3097-3115.

Shepherd, T. G., 2007: Transport in the middle atmosphere. J. Meteor. Soc. Japan, 85B, 165-191.

Ueyama, R., and J. M. Wallace, 2010: To what extent does highlatitude wave forcing drive tropical upwelling in the BrewerDobson circulation? J. Atmos. Sci., 67, 1232-1246.

Vallis, G. K., 2006: Atmospheric and Oceanic Fluid Dynamics: Fundamentals and Large-Scale Circulation. Cambridge University Press, $570 \mathrm{pp}$.

Wallace, J. M., R. L. Panetta, and J. Estberg, 1993: Representation of the equatorial stratospheric quasi-biennial oscillation in EOF phase space. J. Atmos. Sci., 50, 1751-1762.

Yulaeva, E., J. R. Holton, and J. M. Wallace, 1994: On the cause of the annual cycle in tropical lower-stratospheric temperatures. J. Atmos. Sci., 51, 169-174.

Zhou, T., M. A. Geller, and K. Hamilton, 2006: The roles of the Hadley circulation and downward control in tropical upwelling. J. Atmos. Sci., 63, 2740-2757.

-, , and W. Lin, 2012: An observational study on the latitudes where wave forcing drives Brewer-Dobson upwelling. J. Atmos. Sci., 69, 1916-1935. 